\title{
Evaluation of Rice Landraces for Brown Planthopper Resistance Based on Phenotypic Reactions and Biochemical Attributes
}

Debashis Roy ( $\sim$ debashisroy915@gmail.com )

Ramakrishna Mission Vivekananda Educational and Research Institute: Ramakrishna Mission

Vivekananda University https://orcid.org/0000-0001-7603-6403

Abhisek Biswas

University of Milan-Bicocca: Universita degli Studi di Milano-Bicocca

Sukamal Sarkar

Bidhan Chandra Krishi Viswa Vidyalaya Faculty of Agriculture

Gautam Chakraborty

Bidhan Chandra Krishi Viswa Vidyalaya Faculty of Agriculture

Pijush Kanti Sarkar

Bidhan Chandra Krishi Viswa Vidyalaya Faculty of Agriculture

\section{Research Article}

Keywords: Plant resistance, Nilaparvata lugens, defensive components, antixenosis, correlation, PCA

Posted Date: May 4th, 2021

DOl: https://doi.org/10.21203/rs.3.rs-430749/v1

License: (c) (1) This work is licensed under a Creative Commons Attribution 4.0 International License. Read Full License 
2 Evaluation of rice landraces for brown planthopper resistance based on phenotypic reactions and biochemical 3 attributes

4 aDepartment of Agricultural Entomology, Bidhan Chandra Krishi Viswavidyalaya, Nadia, West Bengal 5741252 , India

6 bhaanya Ganga Krishi Vigyan Kendra, Ramakrishna Mission Vivekananda Educational and Research Institute,

$7 \quad$ Murshidabad, West Bengal - 742408, India

8 'Department of Agricultural and Environmental Sciences (DiSAA), University of Milan, Via Celoria 2, Milan 920133 , Italy

10 dDepartment of Agronomy, Bidhan Chandra Krishi Viswavidyalaya, Nadia, West Bengal - 741252, India

11 *Corresponding author's e-mail: debashisroy915@gmail.com (Debashis Roy) 


\section{Abstract}

Brown planthopper (BPH), [Nilaparvata lugens (Stål.)] is an economically important pest of rice (Oryza sativa

L.) throughout Asia, where the damage caused by nymphs and adults, especially during post-tillering to milking stages, significantly reduces grain yield. There is, thus, a pressing need to develop varieties that are resistant to BPH. In this study, the reaction of various rice landraces from Indian origin were assessed (both phenotypically and biochemically) in response to BPH infestation. It was found that the landraces, viz. Badshabhog, Gamra, Haldichuri, Janglijata, Kalabhat, Khara, Adanshilpa, Chikonmashuri, Kerala sundari and Lal dudheshwar exhibited resistance to BPH consistently along with the standard check Ptb33, for three consecutive years under both greenhouse and open-field conditions. These phenotypically resistant rice landraces including Ptb33 exhibited lowest feeding rate, least nymphal and adult preference, minimum survival and higher frequency $(\%)$ of unhatched eggs when compared with the susceptible check (Swarna). Higher levels ascorbic acid, oxalic acid (OA), crude silica (CS), while lower levels of phenols, reducing sugar and total free amino acid (TFA) were expressed in un-infested resistant and moderately resistant landraces. The resistant plants exposed to herbivory by BPH produced higher levels of phenolic compounds, potassium and TFA than plants of susceptible cultivar Swarna. The feeding rate, settling behaviour and survivability of BPH correlated significantly and negatively with OA and CS, whereas the latter showed a significant and positive correlation with egg hatchability.

Keywords: Plant resistance, Nilaparvata lugens, defensive components, antixenosis, correlation, PCA

\section{Declarations}

Funding: The study was funded by Department of Science and Technology (DST), New Delhi, India. The grant number of the concerned funding is DST/INSPIRE/03/2016/003092-IF160926.

Conflicts of interest/Competing interests: The authors have declared that no conflict of interest exists and confirm that there are no disputes over the ownership of the data presented and all contributions have been attributed appropriately.

Availability of data and material: All the data have been presented in the manuscript through table and figure format. The raw data relevant to the study are available at http://doi.org/10.5281/zenodo.4450234

Authors' contributions: The work was carried out in collaboration with all authors. Author DR and GC conceived and designed the research work. DR, SS and GC conducted the laboratory and field experiments and collected data. AB and PKS analyzed data. DR, AB and PKS wrote the manuscript. All authors read and approved the final manuscript.

Ethics approval: This article does not contain any studies with human or other animal subjects. 
59 Acknowledgements: Debashis Roy received the pre-doctoral "Innovation in Science Pursuit for Inspired Research" (INSPIRE) fellowship from Department of Science and Technology (DST), Government of West

61 Bengal, India, New Delhi (Award grant number: DST/INSPIRE/03/2016/003092-IF160926). This work was financially supported by Department of Science and Technology (DST), New Delhi. The authors are grateful to

63 National Rice Research Institute, Cuttack, Odisha, India and Rice Research Station, Chinsurah, West Bengal, India for supplying the standard check varieties and BPH culture, respectively. Authors would also like to show their gratitude to the Director of Research, Bidhan Chandra Krishi Viswavidyalaya, Nadia, West Bengal and the Head, Department of Biological Sciences, Indian Institute of Science Education and Research (IISER), Kolkata, India for providing necessary laboratory facilities. Additionally authors are also grateful to American English editor for final editing of the manuscript.

\section{Key message:}

Phenotypic and biochemical reactions of Indian originated rice landraces were assessed against BPH biotype 4.

$\square$ Landraces viz. Badshabhog, Gamra, Haldichuri, Janglijata, Kalabhat and Khara exhibited resistance.

$\square$ Resistant rice landraces exhibited lowest feeding rate, nymphal and adult preference followed by survival of BPH.

Crude silica and oxalic acid in resistant landraces could reduce the BPH herbivory.

Higher quantity of total phenol and free amino acid was observed in BPH infested resistant rice landraces. 
Rice (Oryza sativa L.) is one of the staple food crops in the world and is used by more than one-third of the human population as a primary source of calories (Xu et al. 2015). Of over twenty insects species recognized as economically important pests of this crop, the brown planthopper (BPH), Nilaparvata lugens (Stål) (Homoptera: Delphacidae) is one of them (Normile 2008; Heong and Hardy 2009). This phloem sap feeder is known to be one of the most destructive and notorious pests of rice throughout Asia and hold the ability to create as high as 60\% yield loss under epidemic conditions (Kumar et al. 2012; Wei et al. 2019). Host-plant resistance to insect injury occurs in plants that use strategies to recover, tolerate or avoid from the attack of pest (Smith 2005); thus, plant characteristics that have negative influences on insect-pest biology, reproduction and development could be used in the screening of plants resistant to insect (Rekha and Singh 2001). The identification of new sources of resistance from landrace, cultivar or germplasms enables the plant breeders to amplify the resistance breeding program through genetic modification (Guo et al. 2019). It has triggered the exploration of resistance sources in rice landraces or traditional folk rice cultivars, which are imperious in different attributes to cultivated rice varieties. The eastern province of India possesses multiple tribal zones, which harbour various rice landraces and also are known to be one of the centres of its origin (Sinha et al. 2015; De 2016). Evaluation of these landraces for true genetic potential, the extent of heterogeneity and biophysical and biochemical differences from commercial varieties is not enrolled elaborately till now. Hence it is essential to gather information on $\mathrm{BPH}$ resistance traits in various rice landraces through phenotypic expression and biochemical analysis. The biophysical factors interfere with feeding, orientation, mating or oviposition mechanisms. In contrast, the biochemical factors are either the primary nutrients or secondary non-nutritional chemicals of plants that affect insect biology. Some of these non-nutritional chemicals are associated with feeding deterrence, repellence or toxicity on insects (Saxena 1986). However, the potential nutritive factors of a plant also play a pivotal role in enhancing its resistance to insects, even in the absence of these chemicals (Mitchell et al. 2016). Thus a strong basis for developing resistant varieties should be aligned towards ascertaining the resistance imparting chemicals and applying those as cues in the breeding program. Host plant shows a varied kind of reactions upon feeding and infesting by insects and alteration of nutritional biochemistry of a plant also takes place in this response (Vanitha et al. 2011). Among the plant chemicals, the presence of increased or decreased amount of nitrogen, potassium, phenolic compounds, reducing sugar, ascorbic acid, crude silica, oxalic acid, free amino acid etc. influence the resistance or susceptibility of rice plants to BPH (Deepa et al. 2016). Keeping these views in backdrop, the present study was undertaken to evaluate different traditional folk rice cultivars of India, 
commonly known as rice landraces to examine their resistance status to BPH biotype 4 and to quantify the levels of BPH feeding attributing plant defensive traits in selected rice landraces, which will form an integral

121 part of sustainable management of BPH through induced resistance.

\section{Materials and Methods}

123 Plant and insect material

124 The study materials consisted of 218 rice landraces collected at farmers' field from different districts of eastern 125 India. All landraces were previously registered under West Bengal Biodiversity Board, Department of 126 Environment, Government of West Bengal, Salt Lake, Kolkata - 700106, India. Seeds of resistant check (Ptb33) 127 and susceptible check (Swarna) were collected from National Rice Research Institute, Cuttack, Odisha germplasm unit. The seeds were sown in screening trays and pots, based on the experiment, containing wellpuddled soil during rainy season in 2016, 2017 and 2018. The insect BPH biotype 4 was reared on the susceptible variety Swarna (Sai Harini et al. 2020) in the insect-proof glasshouse of Bidhan Chandra Krishi Viswavidyalaya $\left(22.9452^{\circ} \mathrm{N}, 88.5336^{\circ} \mathrm{E}\right)$, Nadia, located in West Bengal state of India at $28 \pm 2{ }^{\circ} \mathrm{C}, 75 \pm 5 \%$ relative humidity and 14:10 h light: dark photoperiod. Screening for BPH resistance Free-choice greenhouse screening The Standard seedbox screening test method of IRRI (2002) with suitable modifications by Jena et al. (2006) was followed to evaluate $\mathrm{BPH}$ resistance to 218 selected rice landraces under greenhouse conditions in a complete randomized design and replicated thrice. At the seedling three-leaf stage in the screening trays, $2^{\text {nd }}$ instar nymphs of BPH in the rearing cages were released artificially onto the seedlings by visually ensuring the infestation of each seedling with at least 8-10 nymphs and were monitored at a regular interval for plant damage by BPH. When Swarna plants on one side exhibited intense damage, the entire cage was rotated by $180^{\circ}$ for equal reaction on both sides. After complete wilting of more than 90 per cent of plants of susceptible check due to BPH feeding, the tests were terminated and the damage to all seedling rows was computed and converted to a resistant and susceptible score of 0 (Highly resistant), 1 (Resistant), 3 (Moderately resistant), 5 (Moderately susceptible), 7 (Susceptible) and 9 (Highly susceptible) based on the international standard evaluation system (Horgan et al. 2015).

147 Beside the free-choice test, the no-choice screening was also conducted in the greenhouse by taking 218 numbers of rice landraces to establish their resistance levels against BPH more clearly. The "isolated cage-test 
method" was followed by taking individual plastic pots $(\mathrm{D} \times \mathrm{H}, 8 \times 20 \mathrm{~cm})$ for each landrace (Vos and Jander 2008). Twenty freshly germinated seeds of each landrace were individually seeded concentrically in a single pot including Ptb33 and Swarna. At the seedling three-leaf stage in the pots, $2^{\text {nd }}$ instar nymphs of BPH in the rearing cages were released artificially onto the seedlings by visually ensuring the infestation of all seedlings in a single pot with at least 35-40 nymphs and were encircled with a transparent OHP sheet-made hollow cylindrical structure $(\mathrm{D} \times \mathrm{H}, 6 \mathrm{~cm} \times 30 \mathrm{~cm})$, roofed with 80-mesh insect-proof net pieces at the top. After complete wilting of more than 90 per cent of plants of Swarna, the tests were terminated and the damage was scored according to Horgan et al. (2015), as mentioned earlier.

Open-field screening

Field screening of all the selected rice landraces was carried out at the farmers' fields, having a long history of BPH occurrence and has sufficient water supply system, in the Burdwan district of West Bengal, India during rainy season of 2016, 2017 and 2018. In 2011, this particular district was designated as a BPH biotype 4 endemic zone in India by IRRI (Krishnaiah and Varma 2012). Nursery of all the rice landraces was prepared in each separate straight row by sowing 200-250 pre-soaked germinated seeds at a specific place beside the main field followed by common agronomic practices. Healthy seedlings were transplanted in the manner of single seedling per hill within the layout of each plot $(1 \times 1 \mathrm{~m})$ throughout the field in completely randomized block design and replicated thrice (Bhogadhi and Bentur 2015). Transplanting was done deliberately late at the $2^{\text {nd }}$ fortnight of July with a closer spacing $(\mathrm{r}-\mathrm{r} \times \mathrm{h}-\mathrm{h}, 15 \times 15 \mathrm{~cm})$ to get a maximum infestation of BPH (Satpathi et al. 2012). Manual weeding operation at 25 days after transplanting (DAT) and 45 DAT was done and a $15 \mathrm{~cm}$ water level was maintained for standard BPH multiplication in the field. Scoring based on phenotypic reaction was done when Swarna plots exhibited 'hopper burn' symptoms according to the damage scale 0-9 provided by Sai Harini et al. (2013) from randomly selected 20 plants per replicated plot. Numbers of BPH nymphs and adults per three plants, selected at random from each plot, were also counted simultaneously. At the same time, per cent chaffy grain was enumerated by counting total numbers of spikelets from randomly selected three panicles in each plot at the harvesting stage according to Timmanagouda and Maheswaran (2017).

Phenotyping

Phenotypic tests were conducted in a set of three replications with 40 rice landraces, selected from the results of three years screening (2016-2018) of 218 landraces, in 2019.

Feeding rate by honeydew excretion test 
The honeydew excretion test of BPH was carried out with 30 day-old potted seedlings by the method recounted by Pathak et al. (1982). Five numbers of each $2^{\text {nd }}$ instar nymphs and one-day-old adult females were introduced separately to the bottom portion of the seedling with an orange coloured bromocresol green treated filter paper around the base and an inverted and basal perforated transparent plastic cup (80 $\mathrm{ml}$ volume) on the filter paper incarcerating the insects to the stem portion of about $9 \mathrm{~cm}$ long. The hole of the cup was closed with a ball of non-absorbent cotton to prevent the escape of insects. The honeydew droplets excreted by BPH were turned into blue spots when they came in contact with the filter paper after $48 \mathrm{~h}$ of insect imprisonment. The area marked with blue colour was measured on millimetre squared $\left(\mathrm{mm}^{2}\right)$ graph paper sheet as the extent of feeding and also interpreted statistically.

Settling behaviour of BPH nymphs

This experiment was conducted following the method of Sarao and Bentur (2016) by taking 40 selected landraces seeded at random rows (10 seeds per row), $3.0 \mathrm{~cm}$ apart in a seedbox. The susceptible check Swarna was sown in two frontier rows, while a single row of Ptb33 was in the centre of the box. The 15 day-old seedlings were infested with $2^{\text {nd }}-3^{\text {rd }}$ instar BPH nymphs with at least $12-15$ individuals per seedling and the tray was immediately covered with insect-proof cage to prevent the escape of nymphs. The number of nymphs settled on each seedling was counted at 1, 3 and 5 days after infestation from randomly selected five plants in each row. The seedlings were manually disturbed after each observation for proper reorientation of the BPH nymphs.

\section{Settling behaviour of BPH adults}

The tested landraces were grown in a tray previously filled with fertilizers enriched puddled soil. Around 800 pairs of adults were released onto the 30 day-old seedlings with the help of a giant aspirator under free-choice test, and the tray was again covered with insect-proof cage (Sarao and Bentur 2016). Numbers of adult male and female alighting on various landraces were visually counted at 6, 12, 24, 48, 72 and $96 \mathrm{~h}$ after release. Like nymphal settling test, seedlings were manually disturbed after each count for proper reorientation of the BPH adults.

Nymphal survival

The experiment on nymphal survivability was carried out by caging one-day-old freshly hatched $1^{\text {st }}$ instar BPH nymphs on 15 day-old seedlings (20 nymphs per plant and replicated thrice) of all the landraces separately along with standard check varieties (Jena et al. 2015). The seedlings were monitored at regular interval for consecutive 

seedlings. The per cent nymphal survival was calculated using the formula of Heinrichs et al. (1985).

Ovicidal test

211 Like the nymphal survivability test, one pair of three-day-old BPH adult was confined on 30 day-old seedlings of the tested landraces and check varieties separately, each in three replications. The adults were removed on the $7^{\text {th }}$ day of release and all the seedlings were observed for nymphal hatching from the day onward. The number of hatched nymphs was counted and removed from the plant through an aspirator. After 15-18 days when nymphs stopped coming out, seedlings were collected and dissected under a stereoscopic zoom binocular microscope (40x magnifications) to examine the number of egg masses and the number of unhatched eggs. A total number of eggs were assumed to be the sum of the number of nymphs counted and the number of unhatched eggs. The per cent unhatched eggs were enumerated by using the formula of Khan and Saxena (1985).

$$
\% \text { unhatched eggs }=\frac{\text { number of unhatched eggs }}{(\text { number of nymphs emerged }+ \text { number of unhatched eggs })} \times 100 .
$$

Biochemical study

Bio-chemical analysis of healthy and BPH infested rice plants was carried out for the comparative estimation of total phenol (TP), reducing sugar (RS), ascorbic acid (AS), oxalic acid (OA), crude silica (CS) and total free amino acid (TFA) along with the estimation of nutrient composition viz. nitrogen $(\mathrm{N})$, phosphorus $(\mathrm{P})$ and potassium (K) with 40 selected rice landraces in 2018-2019. This set of experiment was conducted under wellequipped laboratory condition at Department of Biological Sciences, Indian Institute of Science Education and Research (IISER) Kolkata, West Bengal, India. Seeds were sown separately in two plastic containers for each landrace with no additional nutrient. One set of 30 day-old seedlings were infested with $2^{\text {nd }}-3^{\text {rd }}$ instar BPH nymphs for a week. The green leaf sheaths of both healthy and infested plants were used for the biochemical analysis of TP, RS, AS, OA, CS and TFA, while N, P and K were estimated from oven-dried $\left(60{ }^{\circ} \mathrm{C}\right.$ for 72 hours) and ground materials. The detail estimation procedures and the required reagents have been narrated in the supplemental material 1. Total phenol based on the calorimetric assay described by Sadasivam and Manickam (2008). 
237 Estimation and comparison of RS in rice leaf sheath between the healthy and infested plants were made by

238 Dinitrosalicylic Acid Reagent (DNS) method described by Sadasivam and Manickam (2008).

240 Absorbance corresponding to $0.1 \mathrm{ml}$ of test sample $=\mathrm{x} \mathrm{mg}$ of glucose.

241 Ascorbic acid

242 The AS content in healthy and infested rice leaf sheath of different landraces was estimated by the volumetric method described by Sadasivam and Manickam (2008).

Where V1 = known volume and V2 = titrated volume

Oxalic acid

247 Quantitative estimation of OA in healthy and infested plants of rice landraces was done by a direct calorimetric method with Indole reagent by following the method of Bergerman and Elliot (1955).

Crude silica

250

The CS content in both healthy an infested rice plants was estimated through spectrophotometer (Shimadzu, UV-1900) according to the method suggested by Wei-min et al. (2005).

252 Total free amino acid The TFA content in both healthy an infested rice plants was estimated using a spectrophotometer (Shimadzu, UV-1900) by following the method described by Moore and Stein (1948). Nitrogen

One gram each of oven dried plant sample was taken from both healthy and infested plants and $\mathrm{N}$ was estimated on whole plant basis by using the standard micro Kjeldahl method by following Piper (1966) and data was expressed as percentage. Phosphorus and potassium Two-hundred and fifty mg of plant material was digested by wet digestion method according to Piper (1966) using a tri-acid mixture (nitric, sulphuric and perchloric acids in 9:2:1 ratio). The $\mathrm{P}$ and $\mathrm{K}$ were then estimated with the help of a Systonics Digital Flame Photometer (Model S-931) and were expressed as percentage. Statistical analysis The data obtained from different experiments related to mass screening, phenotyping and bio-chemical parameters were analyzed using analysis of variance (ANOVA) with the help of IRRISTAT 4.0 software (Sarao and Bentur 2016) developed by the Biometrics Unit of International Rice Research Institute, the Philippines. 
267 Data which lacked normality were transformed using arcsine and square root transformations before subjected 268 to statistical analysis. Cluster analysis of 218 rice landraces including Ptb33 and Swarna was done based on the 269 similarity in resistance reactions under free-choice, no-choice and field screening and other quantitative parameters like number of BPH and per cent chaffy grains. The similarity matrix was generated through the simple Euclidean distance across all parameters of different landraces, and this matrix was used in a hierarchical clustering technique of Ward's minimum variance method using R software, version 4.0.2 (https://www.Rproject.org). A relationship was established among different bio-physical and bio-chemical parameters of tested rice landraces using pairwise correlation coefficients of their mean values by Pearson correlation with the help of XL-Stats 2020 software (https://www.xlstat.com/en/). Principle Component Analysis (PCA) is one of the most frequently used methods of multivariate data analysis.

277 It was used as a method that transforms an original set of variables into a smaller set of uncorrelated linear variables by retaining most of the information in the former (Ray et al. 2014) and was executed using the XLSTAT 2020 software. The independent factors in the total data set those mostly contributed to the infestation by $\mathrm{BPH}$ on rice were selected for PCA. The total variance is simply the sum of variances of these variables. As they have been standardized to have a variance of one, each observed variable contributes one unit of variance to the total variance in the data set where total nine independent BPH infestation attributing traits were selected for this purpose. The array of communality, the amount of variance of a variable accounted by the common factors together was estimated by the highest correlation coefficient in each array according to Seiller and Stafford (1985). Factor loadings after varimax rotation along with Kaiser Normalization (Kaiser 1974) were estimated for determining the correlation of a variable with a factor. The highest value of the factor loading (squared cosine is the largest) of a particular variable in a particular factor among the extracted factors plays the important role to churn out the factor. After performing PCA, both observations (selected rice landraces) and variables (BPH infestation attributing traits) represented graphically in the factor space through distance biplot analysis (Legendre and Legendre 1998) using XLSTAT 2020 software. The biplot was used to interpret the distances between the observations as these are an approximation of their Euclidean distance in the pdimensional variable space. The position of two observations projected onto a variable vector was used to determine their relative level for this variable.

\section{Results}


The results of 218 rice landraces that were initially screened in the glasshouse as well as in the field during three

297

298

299

300

301

302

303

304

305

306

307

308

309

310

311

312

313

314

315

316

317

318

319

320

321

322

323

324

325 years period for their reactions to brown planthopper and scored on 0-9 scale. The level of resistance was noticed among 218 landraces ranged from 1.2-9.0 (glasshouse) and 1.1-9.0 (field), indicated a wide variation. The 5 landraces viz. Badshabhog, Haldichuri, Janglijata, Kalabhat and Khara were observed as resistant against BPH by showing their damage score (DS) in the range of 1.2-2.0, 1.5-2.8 and 1.1-1.9 under free-choice, nochoice and field screening, respectively. The 218 rice landraces, along with Ptb33 and Swarna, could be easily classified into four major clusters at 8 unit distance by the scale of similarity (Figure 1). Most of the resistant and moderately resistant landraces were grouped under the major cluster I and II, respectively. Cluster III comprised of 46 landraces closest to Swarna in similarity matrix, where most of the landraces showed highly susceptible and susceptible features. However, the majority of moderately susceptible landraces constituted two sub-clusters under the major cluster IV.

Phenotyping

Honeydew excretion

The amount of honeydew excretion is directly proportional to the quantity of food intake by BPH. The quantity of honeydew excreted by BPH nymphs varied significantly among the tested landraces (Table 1). The lowest feeding rate was recorded in Janglijata $\left(27.9 \mathrm{~mm}^{2}\right)$ Badshabhog $\left(30.3 \mathrm{~mm}^{2}\right)$, Kalabhat $\left(30.7 \mathrm{~mm}^{2}\right)$ and Haldichuri $\left(33.3 \mathrm{~mm}^{2}\right)$, respectively, equivalent to Ptb33. Similar trend of honeydew excretion was also observed for one-day-old adult BPH females.

Nymphal settling

Settling behaviour of BPH nymphs differed significantly among the tested landraces, where the least number of nymphs settled on Kalabhat, followed by Ptb33 and Khara (Table 1). All most identical behaviour of nymphal settling was noticed on all the observation days. Overall, the number of nymphs settled $80.00 \%$ less on Kalabhat, $78.12 \%$ on Ptb33 and 73.75\% on Badshabhog concerning the susceptible check Swarna.

Settling behaviour of BPH adults

The significantly lower number of adult males settled on Kalabhat, Ptb33 and Hanumanjata, while Ptb33 and Khara registered a significant lower number of adult females of BPH (Table 1). The observations for both adult males and females were also found to be supplementary to the screening result of the landraces.

Nymphal survival

Mean per cent survival rate of BPH nymphs on phenotypically resistant landraces was lower than on the susceptible check (Table 1). The landraces such as Badshabhog (25.6\%), Janglijata (25.6\%) and Raghushal 
326 (27.1\%) had the lowest survival rates, equivalent to Ptb33 (26.6\%), which were significantly different from

327 Swarna $(96.1 \%)$.

328 Hatching of eggs

329 Among the landraces tested to assess the per cent unhatched eggs of BPH, it was observed that Ptb33 (89.2\%),

330 Haldichuri (83.4\%), Kalabhat (81.2\%) and Badshabhog (78.8\%) had the higher per cent of unhatched eggs, and

331 that in Swarna lowest per cent (24.8\%) of eggs remained unhatched (Table 1).

332 Biochemical components

333 Total phenol

334 The TP content in the leaf sheaths of the BPH infested and healthy rice plants was estimated and differed significantly among the selected rice landraces (Figure 2). In the healthy plants, TP content was found to be 0.28 $\mathrm{mg} \mathrm{g}^{-1}$ tissue in Ptb33, whereas Swarna exhibited $0.48 \mathrm{mg} \mathrm{g}^{-1}$ tissue. After the BPH infestation, per cent increase in TP content was observed in most of the resistant and moderately resistant rice landraces in the range of 22.22 to $51.28 \%$.

Nitrogen

The per cent $\mathrm{N}$ content was not varied significantly among the selected rice landraces, including susceptible checks in case of the healthy plants, while the BPH infested plants showed a significant variation (Figure 3).

342 Higher per cent of $\mathrm{N}$ content was noticed in the moderately susceptible rice landraces (1.25 to $1.61 \%)$ with the highest in Swarna $(1.72 \%)$, but the significant lower range of $\mathrm{N}$ accumulation was found in the resistant landraces $(1.12$ to $1.31 \%)$. Phosphorus Very marginal difference of $\mathrm{P}$ content was observed among the BPH infested rice landraces, which was clear from the value registered by Ptb33 (0.50\%) and Swarna (0.41\%) depicted in Figure 4. Most of the resistant and moderately resistant landraces exhibited an increase in the per cent $\mathrm{P}$ content except Bahurupi (-22.73\%), Kabirajshal (-37.50\%), Lilabati (-31.71\%) and Raghushal (-5.77\%).

Potassium

Unlike $\mathrm{N}$ and $\mathrm{P}$, significant variation in both the healthy and $\mathrm{BPH}$ infested plants was observed in the case of $\mathrm{K}$

352 (Figure 5). Here also, per cent increase in $\mathrm{K}$ was observed in most of the rice landraces, whereas a negative value was encountered in some resistant and moderately resistant landraces. However, Lilabati exhibited a consistent behaviour before and after the $\mathrm{BPH}$ feeding in total $\mathrm{K}$ content. 

varied significantly among all the rice landraces both in healthy and BPH infested plants (Figure 6). Higher quantity of RS was observed in moderately susceptible landraces with the highest in susceptible check Swarna (1.20 $\mathrm{mg} \mathrm{g}^{-1}$ glucose equivalent), compared to Ptb33 (0.35 $\mathrm{mg} \mathrm{g}^{-1}$ glucose equivalent). After BPH feeding, per cent decrease in RS took place in the range of 1.32 to $65.71 \%$, irrespective of all the rice landraces including standard check varieties.

362 Ascorbic acid

Figure 7 revealed that, AS varied significantly among the healthy and BPH infested rice landraces with the reduction of quantity after feeding. Healthy leaf sheaths of Ptb33 (1.15 $\mathrm{mg} \mathrm{g}^{-1}$ tissue) followed by Haldichuri (1.06 $\mathrm{mg} \mathrm{g}^{-1}$ tissue) registered the highest amount of ascorbic acid content compared to Swarna $\left(0.65 \mathrm{mg} \mathrm{g}^{-1}\right.$ tissue), whereas $23.48 \%, 14.15 \%$ and $13.85 \%$ reduction were observed after the infestation by $\mathrm{BPH}$, respectively.

Oxalic acid

Oxalic acid also varied significantly among the selected rice landraces both in healthy and after the infestation by BPH (Figure 8). In the healthy plants, higher range of OA content was noticed in resistant and moderately resistant rice landraces (0.27-0.46 $\mathrm{mg} \mathrm{g}^{-1}$ tissue) and was statistically at par with Ptb33 (0.40 mg g-1 tissue), compared to Swarna ( $0.18 \mathrm{mg} \mathrm{g}^{-1}$ tissue). Per cent reduction in OA was observed irrespective of all the rice landraces including the standard checks after feeding of BPH on them.

374 Crude silica

375 Crude silica content was observed to be significantly higher in resistant and moderately resistant rice landraces (Figure 9). Adanshilpa (17.52\%) followed by Laldudheshwar (16.60\%) exhibited higher CS content and were found to be statistically at par with Gamra (15.85\%), Kalabhat (15.80\%) and Ptb33 (14.53\%). Swarna registered significantly lower CS content and was found to be equivalent with the moderately susceptible landraces. Though the per cent decrease in CS content among all the landraces was observed after the BPH infestation, and higher per cent reduction was shown by the moderately susceptible landraces than those of the resistant landraces.

382 Total free amino acids Total free amino acid content has differed significantly amongst the tested landraces, and the relative quantity was also varied after the infestation of BPH (Figure 10). The highest quantity of TFA was observed in susceptible check Swarna (2148.2 $\mu \mathrm{g} \mathrm{g}^{-1}$ of glutamic acid equivalent), followed by a moderately susceptible 

amount of TFA in the range of 1125.8-1575.2 $\mu \mathrm{g} \mathrm{g}^{-1}$ of glutamic acid equivalent and were statistically at par with Ptb33 (1356.6 $\mu \mathrm{g} \mathrm{g}^{-1}$ of glutamic acid equivalent). However, BPH feeding resulted in the increasing of the quantity of TFA among all the landraces except Maltu.

Correlation studies

Pairwise correlation among the biochemical parameters of rice plants tested in various rice landraces and has been depicted in Table 2 . The plant nutrient $\mathrm{N}$ was non-significantly correlated with all the biochemical factors except K (negatively) and free amino acid (positively), whereas a significant and positive correlation was observed between OA, CS and $\mathrm{K}$ and negative among K, RS and TFA. TP significant but negatively correlated with K, OA and CS while, correlated positively with RS.

Table 3 revealed that, $\mathrm{N}$ content in plants exhibited a significant and positive correlation with honeydew excretion and nymphal survival. P, on the other hand, was significant but negatively correlated with nymphal survival, while both TP and $\mathrm{K}$ showed significant positive and negative correlation with per cent un-hatched eggs and settling of BPH nymphs and adult females, respectively. Both OA and CS correlated significant but negatively with honeydew excretion, settling of nymphs and adult females and nymphal survival, while CS posed a significant and positive impact on per cent un-hatched eggs. In contrast, honeydew excretion, settling of three BPH morphs and nymphal survival correlated significantly and positively with free amino acid. Principal component and diversity analysis Data presented in the tables (Table 4 and 5) revealed that the first, second and third principal components explained about $48.35 \%, 14.08 \%$ and $11.43 \%$ for healthy and $48.89 \%, 13.47 \%$ and $11.59 \%$ for infested plants of the total sample variance respectively. The first three components containing the Eigen values greater than 1 have been retained for the study; hence, the first three components explain the variance of the sample reasonably. Scree-plot test, which is based on the decreasing curve of Eigen values, also provided a transparent visual aid for justification of retaining three components effectively. Table 6 and 7 showed the correlation of variables to the different principal components in the form of the corresponding factor loadings after varimax rotation for healthy and infested plants, respectively. In case of healthy rice plants, the $1^{\text {st }}$ factor consists of $\mathrm{N}$, TP, RS, OS, CS and TFA, while $2^{\text {nd }}, 3^{\text {rd }}$ and $4^{\text {th }}$ factors consist only K, AS and P, respectively. Similarly, N, RS, AS, CS and TFA consisted in $1^{\text {st }}$ factor for BPH infested rice plants, while OA and P shifted into the $4^{\text {th }}$ factor.

414 Here, it has been seen that both RS and AS registered highest squared cosine values (0.828) followed by CS (0.756) in the first factor with maximum load. 
416 The scattered plot matrix score clustered the different biochemical components related to BPH feeding into

417 groups sowing superiority with a mass of selected rice landraces (Figure 11 and 12). It was clear from the biplot

418 that for healthy plants, resistant and moderately resistant landraces including Ptb33 were closely associated with

419 P, CS, AS, OA and K, while with the higher values TP, TFA, N and RS were closely associated with Swarna.

420 Besides, biplot of BPH infested plants exhibited that TFA appeared in close association with resistant landraces

421 and in contrast, AS shifted towards the susceptible check.

\section{Discussion}

423 The resistance of rice to BPH has been studied, documented and reported by several workers and traditional 424 varieties have been identified as most of the resistant donors (Kalode and Krishna 1979; Jena et al. 2006; Jena et al. 2015). Identification of resistant donors is made through the mass screening technique due to its direct relationship with the feeding of the pest. In the present study, the landraces with score ' 1 ', neither preferred both nymphs and adults to feed and settle significantly on them as shreds of evidence from the honeydew and settling tests nor they were allowed for surviving and egg-laying (nymphal survivability and ovicidal test). These findings might be linked to the less ingestion of food and its improper usage impaired the development and survival of BPH on resistant varieties (Alagar et al. 2007). Rate of feeding varied from landrace to landrace, and it determined the food intake by BPH. Feeding can only be determined preciously through computing the area of honeydew excretion and several studies recognized this method as the best for complementing the phenotypic screening (He et al. 2013; Jena et al. 2015). Various plant metabolites present within resistant rice cultivars inhibit the feeding activities of BPH due to the less preference and that was reflected in low honeydew excretion (He et al. 2013). Besides resistant cultivars, significantly lower amounts of honeydew excreted by BPH, when feeding on moderately resistant landraces, confirmed the accuracy of phenotypic screening (Singh et al. 2017) and the possible trend of resistance among the respective rice landraces (Ritu and Ravi 2006). Soundarajan et al. (2002) also conceded that the enumeration of the feeding rate of BPH is a potential indicator to differentiate the resistant and susceptible genotypes of rice.

440 Results of the present study showed that comparatively lower per cent nymphal population of BPH survived on phenotypically resistant rice landraces than Swarna. These results were corroborated by the findings of Vanita et al. (2011) and Kumar et al. (2012), who confirmed the reduced survival and longevity of BPH nymphs and adults on resistant and moderately resistant genotypes. Reduced and poor survival of BPH might be due to the lower feeding rate on resistant landraces, which may be attributable to the lack of phagostimulant or presence of antifeedants (Seo et al. 2009; He et al. 2013; Sable et al. 2015). However, it may also be possible that, these rice 
landraces lack essential nutrients which are solely required for the survival of BPH. Alternatively, Bing et al.

447 (2007) and Syobu et al. (2011) acknowledged regarding some mechanisms or other factors, responsible for

448 preventing ingestion of the required quantity of nutrients from a particular plant, imparted by the resistant

449 landraces. Early embryonic development implied by the onset of eye pigmentation process normally, but

450 hatching of eggs was affected probably due to the failure of developing nymphs to split chorion (Ramulamma

451 2014). Zheng et al. (2017) substantiated the fact that the lower nymphal survival in a rice variety SD15 possibly

452 due to the lower rate of egg hatching and thus tend to be resistant with varying host adaptabilities also supported

453 the present investigation. However, available literatures revealed that, antibiotic resistance levels in some

454 resistant rice accessions were positively associated with the quantity of BPH feeding (Hao et al. 2008; Yang et

455 al. 2017; Han et al. 2018). Therefore, variable resistant traits among different rice landraces could be attributable

456 for the antibiotic reactions against BPH (Darshini and Sidde Gowda 2015). Similar observations were also

457 documented by Kumar et al. (2013), where it has been noticed that resistant rice landraces were statistically at

458 par with Ptb33 in terms of lower per cent egg hatchability, than TN1.

459 Nitrogen $(\mathrm{N})$ content is regarded as an indicator of plant quality which was reported to induce a barrier against

460 the resistance of BPH in rice (Lu and Heong, 2009; Salim 2002). Higher quantity of honeydew excretion by

461 BPH was obtained in susceptible cultivars, and $\mathrm{N}$ was significant and positively correlated with this behaviour.

462 The synergistic relationship between $\mathrm{N}$ in rice leaf and higher feeding rate of BPH possibly due to the ready-

463 made succulence in leaf sheath for higher $\mathrm{N}$ content, which may not affect the insect biology directly, but

464 changes the host biochemistry and plays a significant role in the reduction of plant resistance (Rashid et al.

465 2016). Ramulamma (2014) also indicated that $\mathrm{N}$ was negatively correlated with the resistance of rice against

466 BPH. Moreover, Watanabe and Kitigawa (2000) also documented the effect of BPH feeding on rice plants

467 resulted into the reduction of total $\mathrm{N}$ content and photosynthetic products in the leaf sheath and drastically

468 hampered the plant growth. Results of the present study on the role and impact of N against BPH are also in

469 parity with the elaborative findings of Lu et al. (2004); Lu et al. (2005) and Horgan et al. (2018). Besides N, P

470 and $\mathrm{K}$ are also required by the herbivores for ATP and nucleic acid synthesis along with several physiological

471 activities. Per cent reduction of P in BPH infested rice plants was conceded by Vanitha et al. (2011), while K

472 showed a positive influence with the resistance parameters of rice against BPH (Lu et al. 2005; Amtmann et al.

473 2008). It was very clear from the result that $\mathrm{K}$ had a significant and negative impact on feeding along with BPH

474 settling, survival and reproduction, may be attributable to the distribution of primary metabolites in plant tissues,

475 which in turn could affect the attractiveness of the plant for insects as well as their subsequent growth and 
development on it (Rashid et al. 2017a). However, some workers found that higher level of $\mathrm{K}$ was associated

477 with a lower population of BPH possibly due to the reduced level of RS and TFA in K rich rice cultivars

478 (Vanitha et al. 2011). Correlation and PCA strongly boosted these obtained results and the possible mechanisms were also supported by Rashid et al. (2017b) and Yin et al. (2005). The phenolic compounds were found to be the feeding deterrents to BPH in rice and generally have a positive correlation with host plant resistance (Singh 2004). In the present study, quite lower level of TP was observed in Ptb33 and some resistant landraces compared to susceptible check, where higher per cent increase took place in the resistant landraces. Implication of phloem chemistry of rice, comprises of silicic acid, oxalic acid and phenolic compounds, provokes resistance to BPH (Ghaffar et al. 2011), but the latter usually possess a negative impact over the formers (Ciulu et al. 2018). Grayer et al. (1994) reported that higher silicon content in rice leaf sheath of a resistant variety can reduce the TP content at a lower level without disrupting the phenotypic resistance of the concerned rice variety to BPH. However, Mishra and Misra (1991) found a significantly lower quantity of TP in the resistant varieties Pundia and Handisarakanthi than TN1 and corroborates the findings of the present investigation. Plant vitamins like AS at a higher concentration inhibits the feeding rate of BPH (Sakai and Sogawa 1976) and the statement fully supports the present results in terms of resistance reactions of rice landraces. Both OA and CS were already recognized as the sucking inhibitor against BPH in rice, and in the present experiment a significant and positive correlation was also observed between them. For BPH, reduced performance with impaired feeding behaviours and poor population growth on rice were recorded in higher silicon content cultivars (He et al. 2015; Reynolds et al. 2016; Yang et al. 2017) and positively boosted our findings. The possible mechanisms of plant resistance related to higher silicon content may be the increased rigidity and reduced digestibility of plant tissues due to a physical barrier formed from higher deposition of silica in epidermal cells of rice plants (Massey et al. 2006; Massey and Hartley 2009; Han et al. 2015). Moreover, this physical barrier has a potentiality to reduce the food quality of herbivores and thus impairs their feeding capability followed by the reduction of growth rate (Han et al. 2015; Calandra et al. 2016). In addition, several workers indicated OA as another sucking inhibitor beside silicon (Yoshihara et al. 1979), and Nagata and Hayakawa (1998) found some antifeeding activity of OA against BPH. The TFA also played a significant role in BPH infestation on rice where most of the resistant landraces, including Ptb33 registered lower TFA content. This might be attributable that resistant cultivars against sap suckers usually possess a lower quantity of TFA by limiting the nutritive value of plant tissues for the herbivores Golan et al. (2017). Biplot of PCA suggests that TFA, RS and N content were in a close 

corroborated the findings of Sempruch et al. (2011). Although, it is still not clear by the researchers regarding

508 the mechanisms of resource allocation when attacked by herbivores, but it can be hypothesized that higher cell

509 damage would make the plant resource sequestration a possible preferred strategy (Orians et al. 2011).

510 Moreover, Rashid et al. (2017b) linked higher K level with a lower level of TFA in the rice plants and observed

511 the increment of both the compounds after BPH feeding.

512 In conclusion, it may be suggested that the activity of various nutrients and some biochemical components like

513 OA, CS, and TFA in resistant landraces could reduce the feeding rate, nymphal and adult preference, survival 514 and egg hatching of BPH which may in turn be useful in developing IPM strategy of BPH in rice. 515 Understanding these biochemical mechanisms underlying resistance in rice landraces will also contribute to the 516 effective management of BPH and facilitate resistance breeding program more efficiently.

\section{$517 \quad$ References}

518 Alagar M, Suresh S, Samiyappan R, Saravanakumar D (2007) Reaction of resistant and susceptible rice 519 genotypes against brown planthopper (Nilaparvata lugens). Phytoparasitica 35:346-356. https://doi.org/10.1007/BF02980697

Amtmann A, Troufflard S, Armengaud P (2008) The effect of potassium nutrition on pest and disease resistance in plants. Physiol Plant 133(4): 682-691.

Bergerman J, Elliot JS (1955) Method for direct calorimetric determination of oxalic acid. Anal Chem 27(6):1014-1015. https://doi.org/10.1021/ac60102a045

Bhogadhi SC, Bentur JS (2015) Screening of rice genotypes for resistance to brown planthopper biotype 4 and detection of BPH resistance genes. Int J Life Sci Biotech Pharm Res 4(2):90-95.

Bing L, Dong H, Zhang M, Xu D, Wang J (2007) Potential resistance of tricin in rice against brown planthopper Nilaparvata lugens (Stål). Acta Ecol Sin 27:1300-1306. https://doi.org/10.1016/S1872-2032(07)60031-6

Calandra I, Zub K, Szafra_nska P A, Zalewski A, Merceron G (2016) Silicon-based plant defences, tooth wear and voles. The J Exp Biol 219: 501-507. https://doi.org/10.1242/jeb.134890

531 Ciulu M, Cadiz-Gurrea ML, Segura-Carretero A (2018) Extraction and analysis of phenolic compounds in rice. Molecules 23(11): 2890. https://doi.org/10.3390/molecules23112890

533 Darshini GM, Sidde Gowda DK (2015) Reaction of rice landraces to the brown planthopper Nilaparvata lugens (Homoptera: Delphacidae). Trends Biosci 8: 4164-4168. 
De Vos M, Jander G (2008) Choice and no-choice assays for testing the resistance of A. thaliana to chewing insects. J Vis Exp 15: e683. https://doi.org/10.3791/683

De M (2016) Qualitative assessment of 30 folk rice (Oryza sativa L.) varieties of West Bengal using descriptor codes. SCOTOPIA - A multidisciplinary Bi-annual Journal 1(2):40-48.

Deepa K, Pillai MA, Murugesan N (2016) Biochemical bases of resistance to brown planthopper (Nilaparvata lugens) (Stål.) in different rice accessions. Agric Sci Digest 36:102-105. https://doi.org/10.18805/asd.v36i2.10627

Ghaffar MB, Pritchard J, Ford-Lloyd B (2011) Brown planthopper (N. lugens Stål) feeding behaviour on rice germplasm as an indicator of resistance. PLoS ONE 6(7):e22137. https://doi.org/10.1371/journal.pone.0022137

Golan K, Sempruch C, Gorska-Drabik E, Czerniewicz P, Lagowska B, Kot I, Kmiec K, Magierowicz K, Leszczynski B (2017) Accumulation of amino acids and phenolic compounds in biochemical plant responses to feeding of two different herbivorous arthropod pests. Arthropod-Plant Interactions 11(5):675-682. https://doi.org/10.1007/s11829-017-9522-8

Grayer RJ, Kimmins FM, Stevenson PC, Stevenson JB, Wijayagunesekera HNP (1994) Phenolics in rice phloem sap as sucking deterrents to the brown planthopper (Nilaparvata lugens). Acta Hortic 381:391394. https://doi.org/10.17660/ActaHortic.1994.381.100

Guo T, Liao C, Chuang W (2019) Defensive responses of rice cultivars resistant to Cnaphalocrocis medinalis (Lepidoptera: $\quad$ Crambidae). Arthropod-Plant Interactions 13:611-620. https://doi.org/10.1007/s11829-019-09673-4

Han Y, Lei W, Wen L, Hou M (2015) Silicon-mediated resistance in a susceptible rice variety to the rice leaf folder, Cnaphalocrocis medinalis Guenée

(Lepidoptera:

Pyralidae). PLoS ONE 10:e0120557. https://doi.org/10.1371/journal.pone.0120557

Han Y, Wu C, Yang L, Zhang D, Xiao Y (2018) Resistance to Nilaparvata lugens in rice lines introgressed with the resistance genes Bph14 and Bph15 and related resistance types. PLoS ONE 13:e0198630. https://doi.org/10.1371/journal.pone.0198630

Hao P, Liu C, Wang Y, Chen R, Tang M, Du B, Zhu L, He G (2008) Herbivore-induced callose deposition on the sieve plates of rice: An important mechanism for host resistance. Plant Physiol 146:1810-1820. https://doi.org/10.1104/pp.107.111484 
He W, Yang M, Li Z, Qiu J, Liu F, Qu X, Qiu Y, Li R (2015) High levels of silicon provided as a nutrient in hydroponic culture enhances rice plant resistance to brown planthopper. Crop Protec 67:20-25. https://doi.org/10.1016/j.cropro.2014.09.013

He J, Liu YQ, Liu YL, Jiang L, Wu H, Kang HY, Liu SJ, Chen LM, Liu X, Cheng XN, Wan JM (2013) High-resolution mapping of brown planthopper (BPH) resistance gene Bph27(t) in rice. Mol Breed 31:549-557. https://doi.org/10.1007/s11032-012-9814-8

Heinrichs EA, Medrano FG, Rapusas HR (1985) Genetic evaluation for insect resistance in rice. Los Banos, the Philippines: International Rice Research Institute: 1-355.

Heong KL, Hardy B (2009) Planthoppers: New Threats to the Sustainability of Intensive Rice Production Systems in Asia. Los Banos, the Philippines: International Rice Research Institute: 1-460.

Horgan FG, Ramal AF, Bentur JS, Kumar R, Bhanu KV, Sarao PS, Iswanto EH, Chien HV, Bernal CC, Phyu M H, Almazan MLP, Alam MZ, Lu ZX, Huang SH (2015) Virulence of brown planthopper (Nilaparvata lugens) populations from South and South East Asia against resistant rice varieties. Crop Protect 78:222231. https://doi.org/10.1016/j.cropro.2015.09.014

Horgan FG, Cruz AP, Bernal CC, Ramal AF, Almazan MLP, Wilby A (2018) Resistance and tolerance to the brown planthopper, Nilaparvata lugens (Stål), in rice infested at different growth stages across a gradient of nitrogen applications. Field Crops Res 217:53-65. https://doi.org/10.1016/j.fcr.2017.12.008

IRRI (2002) Standard Evaluation System for Rice. International Rice Research Insti-tute, Manila, Philippines.

Jena KK, Jeung JU, Lee JH, Choi HC, Brar DS (2006) High-resolution mapping of a new brown planthopper (BPH) resistance gene, Bph18(t), and marker-assisted selection for BPH resistance in rice (Oryza sativa L.). Theor Appl Genet 112:288-297. https://doi.org/10.1007/s00122-005-0127-8

Jena M, Panda RS, Sahu RK, Mukherjee AK, Dhua U (2015) Evaluation of rice genotypes for rice brown plant hopper resistance through phenotypic reaction and genotypic analysis. Crop Protec 78:119-126. https://doi.org/10.1016/j.cropro.2015.08.020

Kaiser HF (1974) An index of factorial simplicity. Psychometrika 39:31-36.

Kalode MB, Khrishna TS (1979) Varietal resistance to brown planthopper in India. In: Brown Planthopper: Threat to Rice Production in Asia. International Rice Research Institute, Philippines, pp. 187-200. 
Khan ZR, Saxena RC (1985) Behavioural and physiological responses of Sogatella furcifera (Horvath) (Delphacidae: Hemiptera) to selected resistant and susceptible rice cultivars. J Econ Entomol 78(6):1280-1286. https://doi.org/10.1093/jee/78.6.1280

Krishnaiah K, Varma NRG (2012) Changing insect pest scenario in the rice ecosystem - A national perspective. Directorate of Rice Research Rajendranagar, Hyderabad, pp. 2-8.

Kumar H, Maurya RP, Tiwari SN (2012) Study on antibiosis mechanism of resistance in rice against brown plant hopper, Nilaparvata lugens (Stål.). Ann Pl Protec Sci 20:98-101.

Kumar MN, Shashibhushan V, Lakshmi VJ, Mohan M, Ramesh B (2013) Qualitative and quantitative changes in biochemical constituents in the rice plant treated with different xenobiotics. J Agril Sci Technol 3: 1725.

Legendre P, Legendre L (1998) Numerical Ecology. Second English Edition. Elsevier, Amsterdam, 403-406.

Lu ZX, Heong KL (2009) Effects of nitrogen-enriched rice plants on ecological fitness of planthoppers. In: Heong K L, Hardy B. Planthoppers: New Threats to the Sustainability of Intensive Rice Production Systems in Asia. Manila, the Phillipines: International Rice Research Institute: 247-256.

Lu ZX, Heong KL, Yu XP, Hu C (2005) Effects of nitrogen on the tolerance of brown planthopper, Nilaparvata lugens to adverse environmental factors. Insect Sci 12(2):121-128. https://doi.org/10.1111/j.17447917.2005.00014.x

Lu ZX, Heong KL, Yu XP, Hu C (2004) Effects of plant nitrogen on ecological fitness of the brown planthopper, Nilaparvata lugens (Stål) in rice. J Asia-Pacific Entomol 7(1):97-104. https://doi.org/10.1016/S1226-8615(08)60204-6

Massey FP, Hartley SE (2009) Physical defences wear you down: Progressive and irreversible impacts of silica on insect herbivores. J An Ecol 78:281-291. https://doi.org/10.1111/j.1365-2656.2008.01472.x

Massey FP, Ennos AR, Hartley SE (2006) Silica in grasses as a defence against insect herbivores: Contrasting effects on folivores and a phloem feeder. J An Ecol 75:595-603. https://doi.org/10.1111/j.1365$\underline{2656.2006 .01082 . x}$

Mishra NC, Misra BC (1991) Effect of white backed planthopper Sogatella furcifera infestation on the biochemical composition of rice varieties. Environ Ecol 6:467-469.

Mitchell C, Brennan RM, Graham J, Karley AJ (2016) Plant defense against herbivorous pests: Exploiting resistance and tolerance traits for sustainable crop protection. Front Plant Sci 7:1132. https://doi.org/10.3389/fpls.2016.01132 
Moore S, Stein WH (1948) Photometric ninhydrin method for use in the chromatography of amino acids. J Biol Chem 176:367-388.

Nagata T, Hayakawa T (1998) Antifeeding activity of aconitic acids and oxalic acid on brown planthopper, Nilaparvata lugens (Stål) and green leaf hopper, Nephotettix cincticeps (Uhler). Japanese J Appl Ent Zool 42(3):115-121.

Normile D (2008) Reinventing rice to feed the world. Science 321:330-333. https://doi.org/10.1126/science.321.5887.330

Orians CM, Thorn A, Gomez S (2011) Herbivore-induced resource sequestration in plants: why bother? Oecologia 167:1-9. https://doi.org/10.1007/s00442-011-1968-2

Pathak PK, Saxena RC, Heinrichs EA (1982) Parafilm sachet for measuring honeydew excretion by Nilaparvata lugens on rice. J Econ Entomol 75(2):194-195. https://doi.org/10.1093/jee/75.2.194

Piper CS (1966) Soil and Plant Analysis, Hans publishers, Bombay, 137-153.

Ramulamma A (2014) Host plant resistance in paddy to brown planthopper, Nilaparvata lugens (Stål). M.Sc. thesis, Acharya N.G. Ranga Agricultural University, Hyderabad, p. 55.

Rashid MM, Ahmed N, Jahan M, Islam KS, Nansen C, Willers JL, Ali MP (2017a) Higher fertilizer inputs increase fitness traits of brown planthopper in rice. Sci Rep 7:4719. https://doi.org/10.1038/s41598-017$\underline{05023-7}$

Rashid MM, Jahan M, Islam KS (2016) Impact of nitrogen, phosphorus and potassium on brown planthopper and tolerance of its host rice plants. Rice Sci 23(3):119-131. https://doi.org/10.1016/j.rsci.2016.04.001

Rashid MM, Jahan M, Islam KS, Latif MA (2017b) Ecological fitness of brown planthopper, Nilaparvata lugens (Stål.) to rice nutrient management. Ecol Procs 6:15. https://doi.org/10.1186/s13717-017-0080-X

Ray K, Dutta J, Banerjee H, Biswas R, Phonglosa A, Pari A (2014) Identification of principal yield attributing traits of Indian mustard Brassica juncea 1. Czernj and Cosson using multivariate analysis. The Bioscan 9(2):803-09.

Rekha R, Singh R (2001) Sources and mechanisms of resistance in rice against rice leaffolder Cnaphalocrocis medinalis (Guenee) - a review. Agric Rev 22(1):1-12.

Reynolds OL, Padula MP, Zeng R, Gurr GM (2016) Silicon: Potential to promote direct and indirect effects on plant defense against arthropod pests in agriculture. Front Plant Sci 7:744. https://doi.org/10.3389/fpls.2016.00744

Ritu RS, Ravi RS (2006) Evaluation of rice germplasm against brown planthopper. J Rice Res 2:27-32. 
Sable A, Suresh S, Kumar M (2015) Antibiosis mechanism of resistance in rice genotypes against brown planthopper Nilaparvata lugens (Stål.). Eco Env Cons 21:545-548.

Sadasivam S, Manickam A (2008) Biochemical methods, $3^{\text {rd }}$ edition. New Age International Publisher (P) Limited, New Delhi, India. ISBN: 81-224-0976-8

Sai Harini A, Dass MA, Surapaneni SK, Balaravi P (2020) Mapping of quantitative trait loci associated with resistance to brown planthopper in background of Swarna from a traditional variety Ptb33. Euphytica 216: 114. https://doi.org/10.1007/s10681-020-02652-4

Sai Harini A, Sai Kumar S, Padma B, Richa S, Ayyappa M, Vinay S (2013) Evaluation of rice genotypes for brown planthopper (BPH) resistance using molecular markers and phenotypic methods. African $\mathbf{J}$ Biotech 12(19):2515-2525. https://doi.org/10.5897/AJB2013.11980

Sakai T, Sogawa K (1976) Effects of nutrient compounds on sucking response of the brown planthopper Nilaparvata lugens (Stål) (Homoptera: Delphacidae). Appl Entomol Zool 11:82-88.

Salim M (2002) Nitrogen induced changes in rice plants: Effect on host-insect interactions. Pak J Agric Res 17(3):210-220.

Sarao PS, Bentur JS (2016) Antixenosis and tolerance of rice genotypes against brown planthopper. Rice Sci 23(2):96-103. http://dx.doi.org/10.1016/j.rsci.2016.02.004

Satpathi CR, Chakraborty K, Acharjee P (2012) Impact of seedling spacing and fertilizer on brown planthopper, Nilaparvata lugens Stål. incidence in rice field. J Biol Chem Res 29(1):26-36.

Saxena RC (1986) Biochemical bases of resistance in rice varieties. In. Natural resistance of plants to pests: Role of Allelochemicals (Eds. M.B. Green and P.A. Hedin). American Chemical Society, Washington D.C. pp. 142-159.

Seiller GJ, Stafford RE (1985) Factor analysis of components in Guar. Crop Sci 25(6):905-908.

Sempruch C, Michalak A, Leszczynski B (2011) Effect of grain aphid (Sitobion avenae Fabricius, 1775) feeding on content of free amino acids within selected parts of triticale plants. Aphids Other Hemipterous Insects 17:139-145.

Seo BY, Jung JK, Choi BR, Park HM, Lee BH (2009) Resistance-breaking ability and feeding behaviour of the brown planthopper, Nilaparvata lugens, recently collected in Korea. In: Heong, K.L., Hardy, B. (eds), Planthoppers: New Threats to the Sustainability of Intensive Rice Production Systems in Asia. International Rice Research Institute. Los Banos, Philippines. pp. 303-314. 
681

682

683

684

685

686

687

688

689

690

691

692

693

694

695

696

697

698

699

700

701

702

703

704

705

706

707

708

709

Singh HV (2004) Biochemical transformation in Brassica spp. due to Pernospora parasitica infection. Annl Plant Protec Sci 12:301-304.

Singh I, Sarao PS, Sharma N (2017) Antibiosis components and antioxidant defence of rice as mechanism of resistance to brown planthopper, Nilaparvata lugens (Stål). Cereal Res Commun 45:284-295. https://doi.org/10.1556/0806.45.2017.011

Sinha AK, Mallick GK, Mishra PK (2015) Diversity of grain morphology on traditional rice varieties (Oryza sativa L.) of lateritic region of West Bengal. World J Agril Sci 11(1):48-54. https://doi.org/10.5829/idosi.wjas.2015.11.1.1843

Smith CM (2005) Plant resistance to arthropods: molecular and conventional approaches. Springer, Berlin.

Soundarajan RP, Gunathilagaraj K, Chitra N (2002) Antixenosis resistance to brown planthopper, Nilaparvata lugens (Stål) in rice. Annl Plant Protec Sci 10:23-27.

Syobu S, Otuka A, Matsumura M (2011) Trap catches of the small brown planthopper, Laodelphax striatellus (Fallen) (Hemiptera: Delphacidae), in Northern Kyushu district, Japan in relation to weather conditions. Appl Entomol Zool 46: 41-50. https://doi.org/10.1007/s13355-010-0005-y

Timmanagouda SP, Maheswaran M (2017) Phenotypic screening for Brown planthopper [Nilaparvata lugens (Stål)] resistance in rice (Oryza sativa L.). Int J Curr Microbiol Appl Sci 6(12):858-863. https://doi.org/10.20546/ijcmas.2017.612.092

Vanitha K, Suresh S, Gunathilagaraj K (2011) Influence of brown planthopper Nilaparvava lugens (Stål.) feeding on nutritional biochemistry of rice plant. Oryza 48(2):142-146.

Watanabe T, Kitagawa H (2000) Photosynthesis and translocation of assimilates in rice plants following phloem feeding by the planthopper Nilaparvata lugens (Homoptera: Delphacidae). J Econ Entomol 93:1192-1198. https://doi.org/10.1603/0022-0493-93.4.1192

Wei S, Zhang H, Li B, Ji J, Shao X (2019) Insecticidal effect of aconitine on the rice brown planthoppers. PLoS ONE 14:e0221090. https://doi.org/10.1371/journal.pone.0221090

Wei-min D, Ke-qin Z, Bin-wu D, Cheng-xiao S, Kang-le Z, Run C, Jie-yun Z (2005) Rapid determination of silicon content in rice. Rice Sci 12(2):145-147.

Xu HX, Zheng XS, Yang YJ, Tian JC, Lu YH, Tan KH, Heong KL, Lu ZX (2015) Methyl eugenol bioactivities as a new potential botanical insecticide against major insect pests and their natural enemies on rice (Oryza sativa). Crop Protec 72:144-149. https://doi.org/10.2016/j.cropro.2015.03.017 

population growth in the phloem feeder Nilaparvata lugens (Hemiptera: Delphacidae). Sci Rep 7:1101. https://doi.org/10.1038/s41598-017-01060-4

713 Yin JL, Wu JC, Yu YS, Liu JL, Xie M, Wan FH (2005) Comparison of the effects of brown planthopper, Nilaparvata lugens (Stål.) (Homoptera: Delphacidae) and rice leaf folder, Cnaphalocrocis medinalis Guenee (Lepidoptera: Pyralidae) infestations and simulated damage on nutrient uptake by the roots of rice plants. Environ Entomol 34(6):1614-1620. https://doi.org/10.1603/0046-225X-34.6.1614

Yoshihara T, Sogawa K, Pathak MD, Villareal R (1979) Comparison of oxalic acid concentration in rice varieties susceptible to the brown planthopper. Int Rice Res Newsl 4:10-11.

719
Zheng XM, Tao YL, Chi H, Wan FH, Chu D (2017) Adaptability of small brown planthopper of four rice cultivars using life table and population projection method. Sci Rep 7:42399. https://doi.org/10.1038/srep42399 
741 Fig. 1

742 Circular cluster dendrogram based on similarity matrix enumerated from 218 rice landraces (RL) and 2 standard

743 checks (Ptb33 and Swarna) varieties. The dendrogram was created using Ward.D2 package.

744 Fig. 2

745 Total phenol (TP) content in the healthy and BPH infested rice landraces.

$746 \quad$ Fig. 3

747 Nitrogen $(\mathrm{N})$ content in the healthy and BPH infested rice landraces.

$748 \quad$ Fig. 4

749 Phosphorus (P) content in the healthy and BPH infested rice landraces.

$750 \quad$ Fig. 5

751 Potassium $(\mathrm{K})$ content in the healthy and BPH infested rice landraces.

$752 \quad$ Fig. 6

753 Reducing sugar (RS) content in the healthy and BPH infested rice landraces.

$754 \quad$ Fig. 7

755 Ascorbic acid (AS) content in the healthy and BPH infested rice landraces.

$756 \quad$ Fig. 8

757 Oxalic acid (OA) content in the healthy and BPH infested rice landraces.

$758 \quad$ Fig. 9

759 Crude silica (CS) content in the healthy and BPH infested rice landraces.

$760 \quad$ Fig. 10

761 Total free amino acid (TFA) content in the healthy and BPH infested rice landraces.

$762 \quad$ Fig. 11

763 Scattered plot matrix score of healthy $(\mathrm{H})$ rice landraces and biochemical components.

$764 \quad$ Fig. 12

765 Scattered plot matrix score of infested (I) rice landraces and biochemical components. 


\section{Figures}

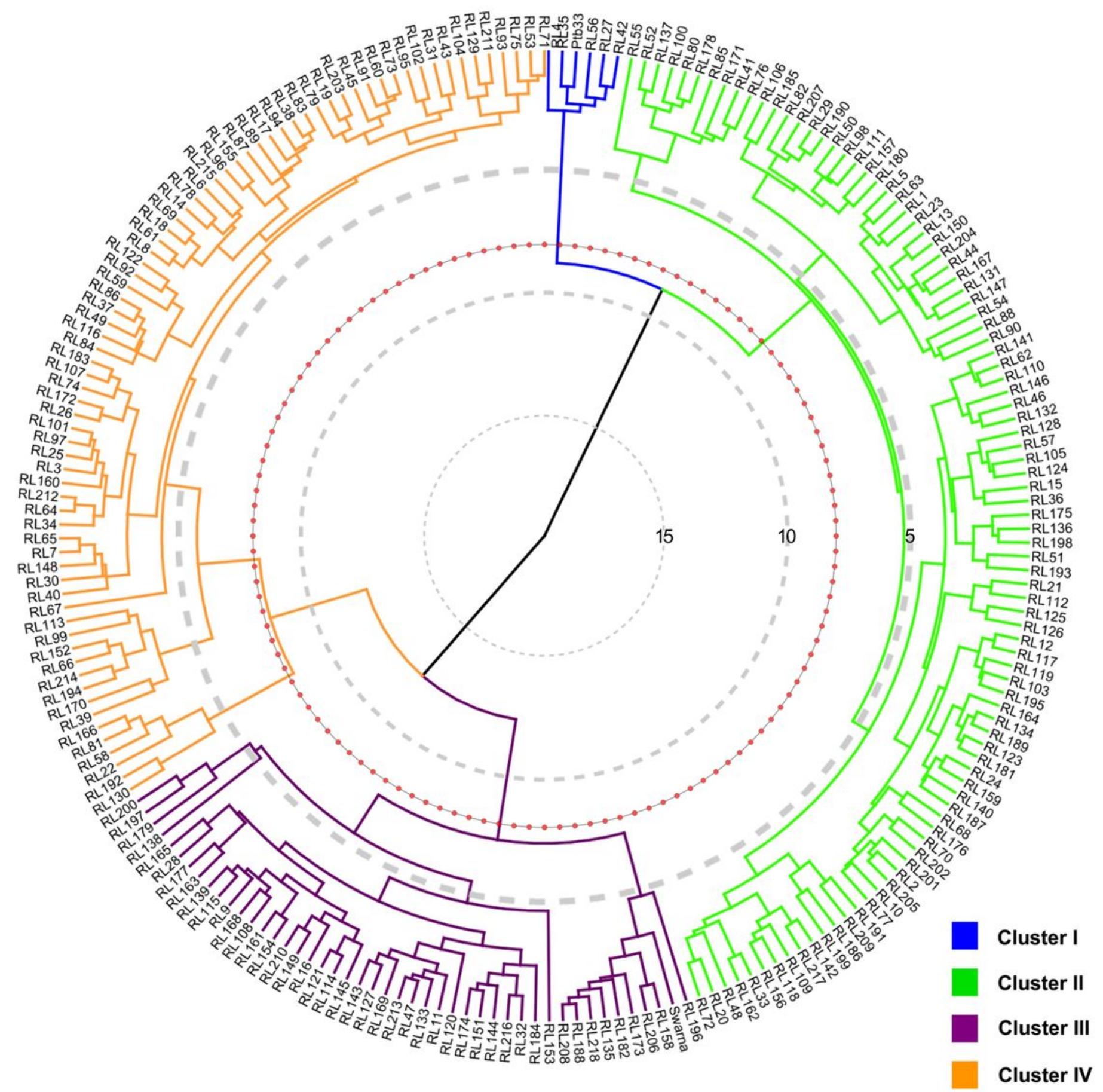

Figure 1

Circular cluster dendrogram based on similarity matrix enumerated from 218 rice landraces $(R L)$ and 2 standard checks (Ptb33 and Swarna) varieties. The dendrogram was created using Ward.D2 package. 


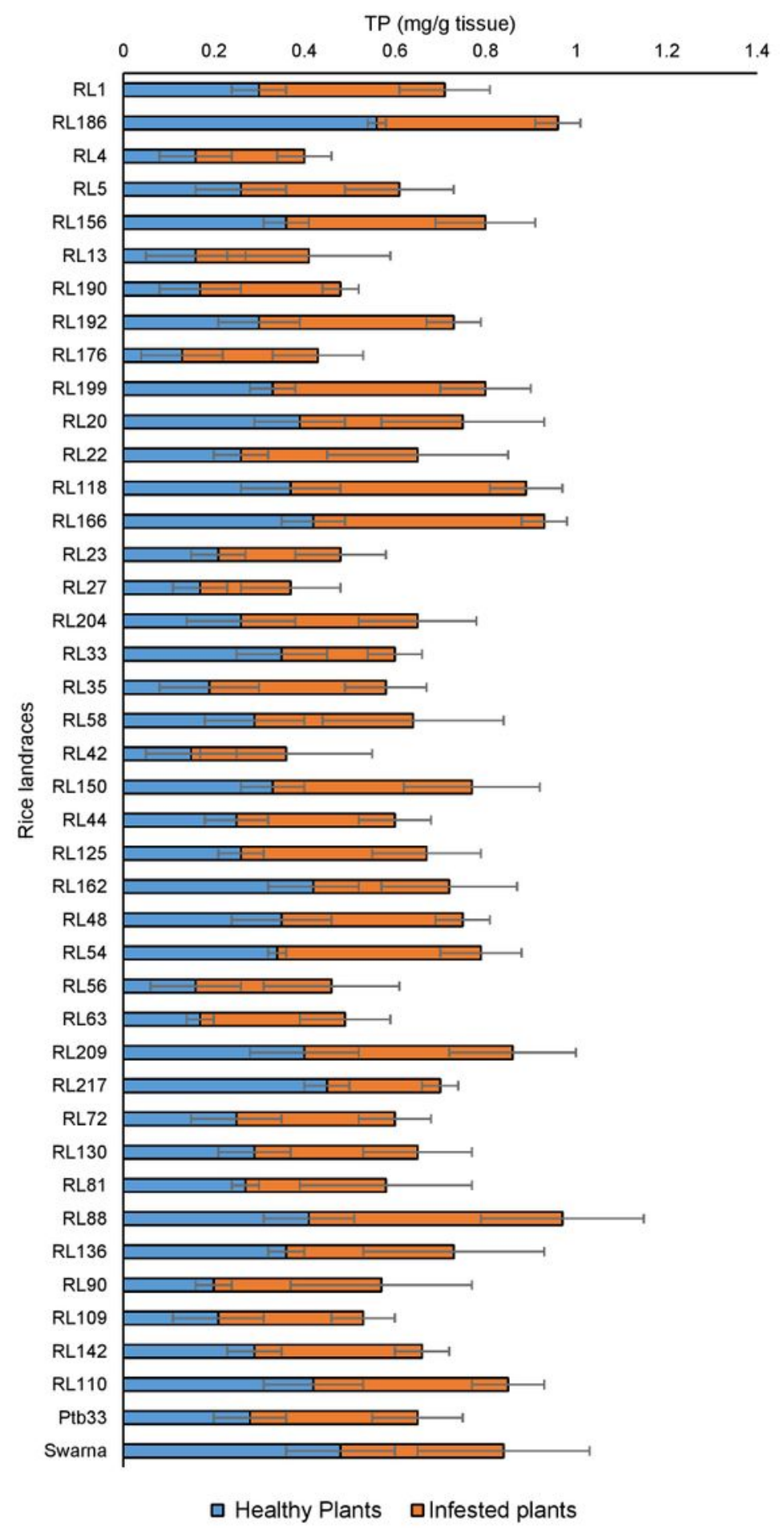

Figure 2

Total phenol (TP) content in the healthy and BPH infested rice landraces. 


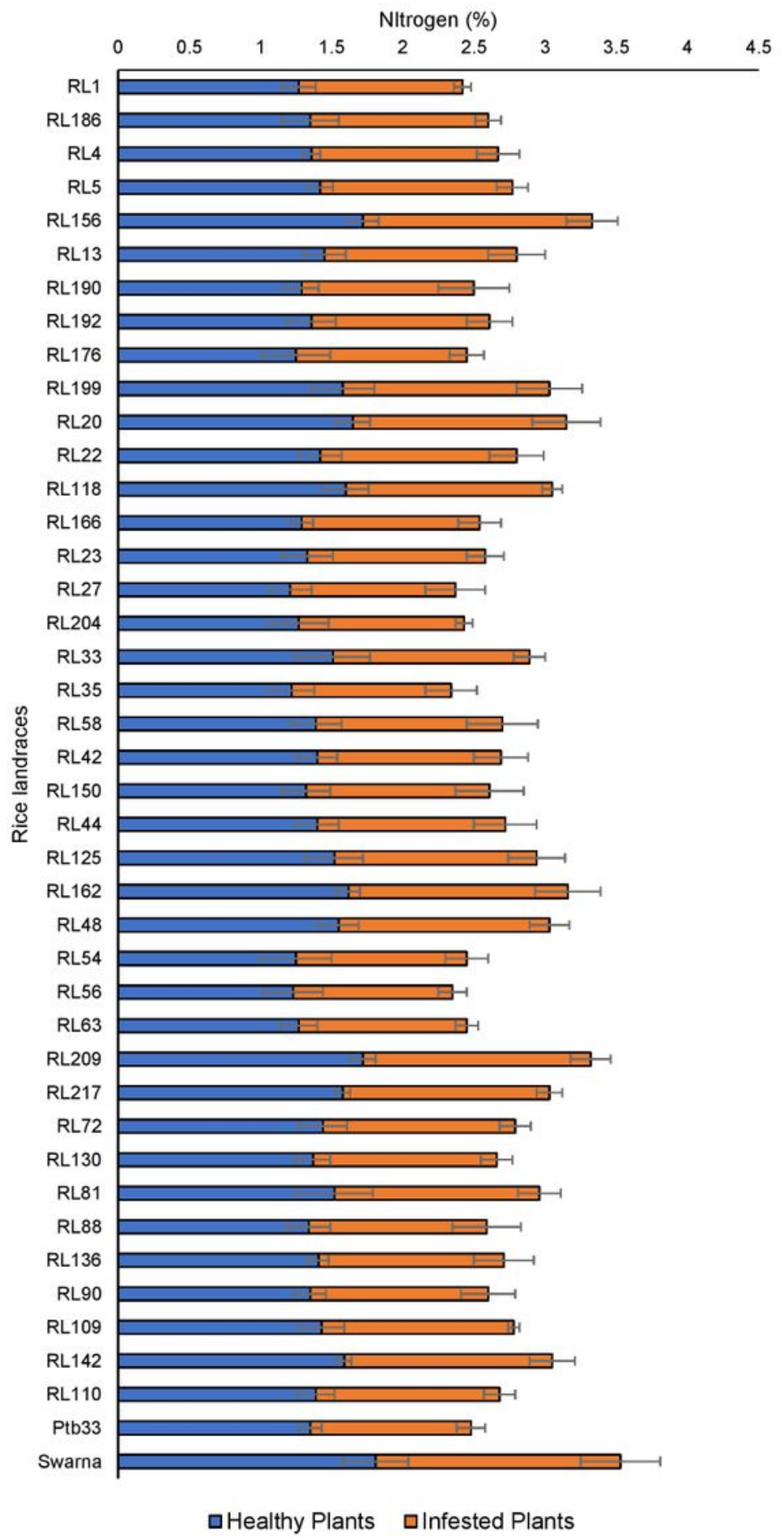

Figure 3

Nitrogen $(\mathrm{N})$ content in the healthy and BPH infested rice landraces. 


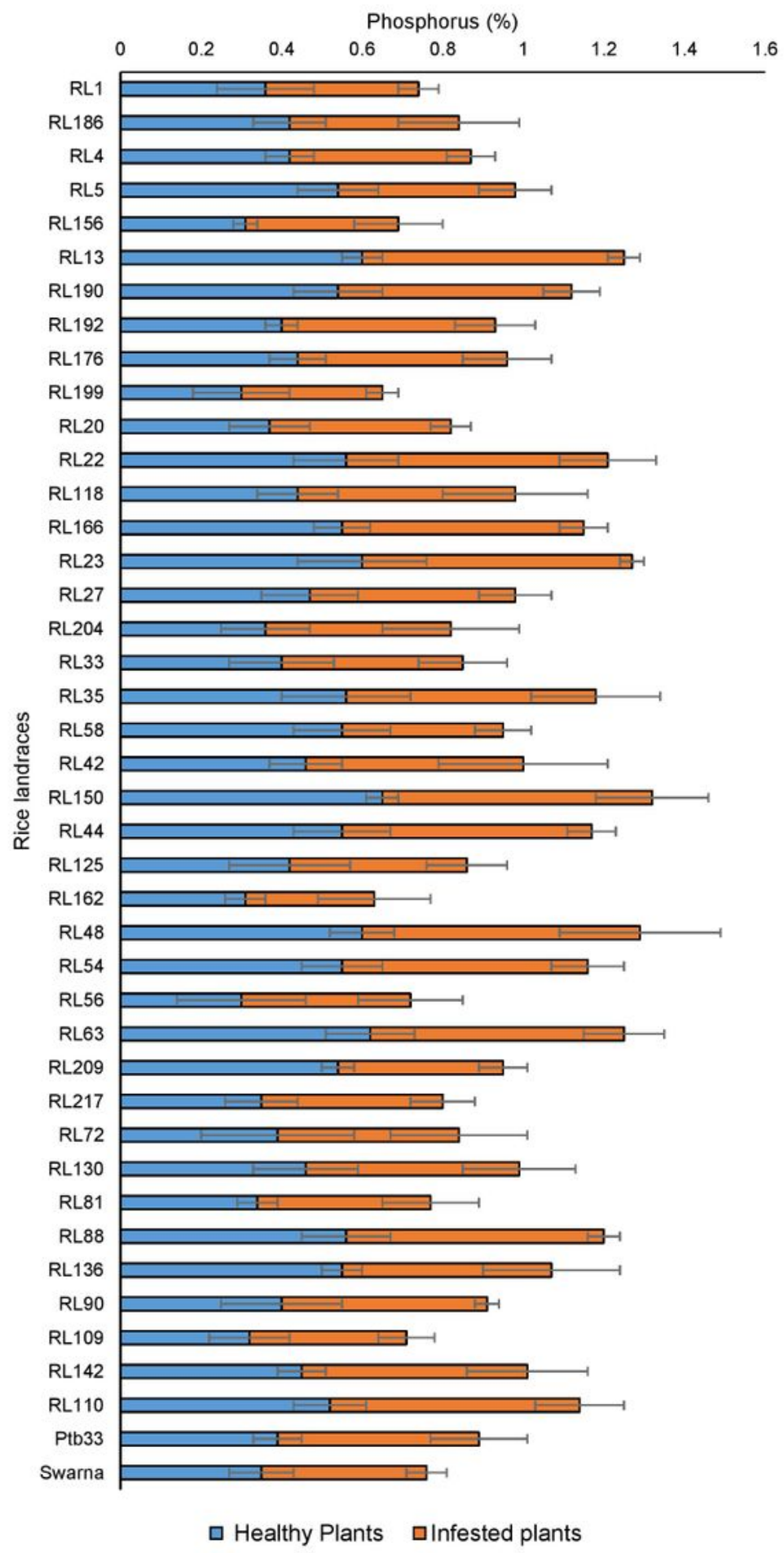

Figure 4

Phosphorus $(\mathrm{P})$ content in the healthy and BPH infested rice landraces. 


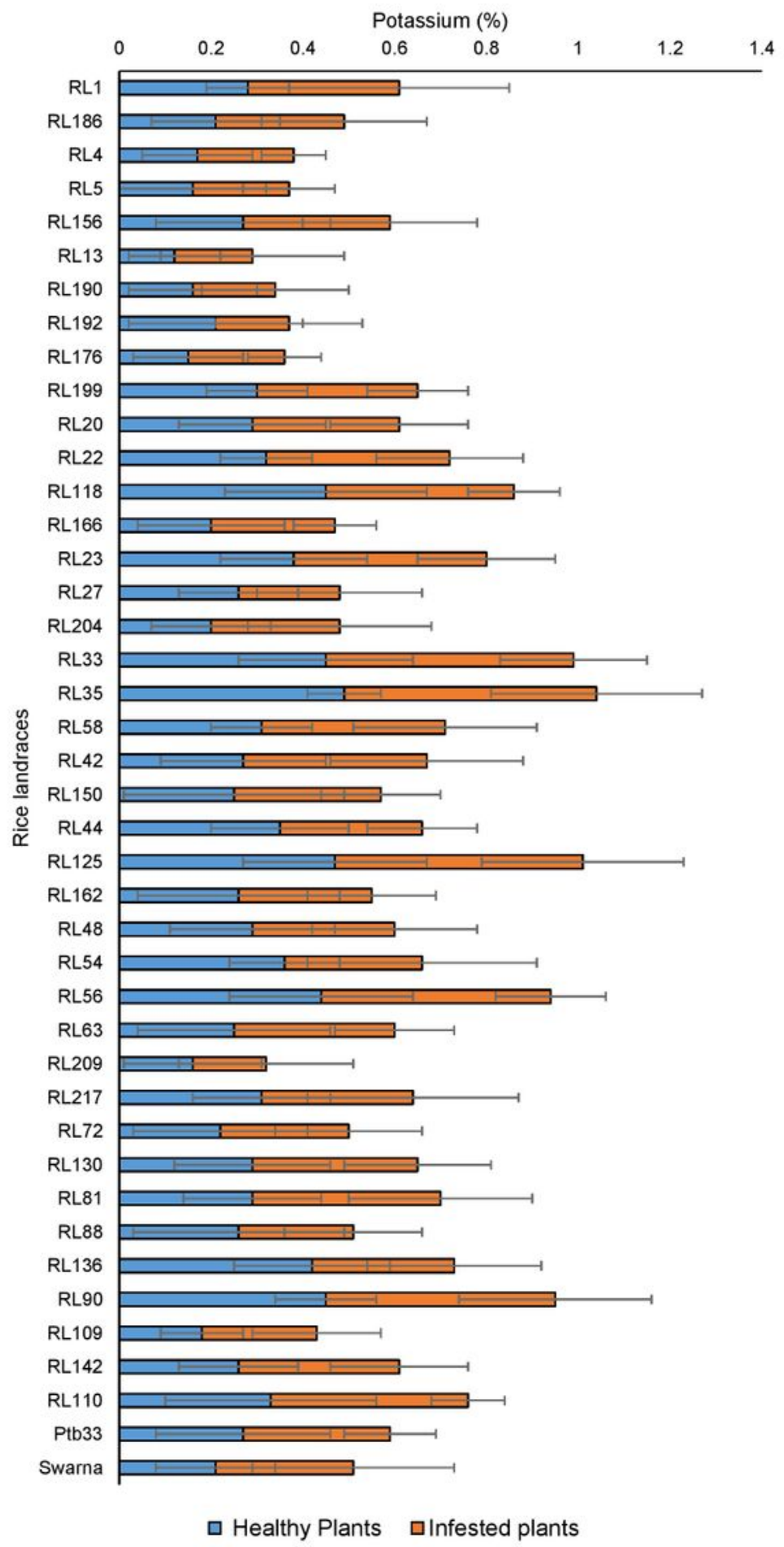

Figure 5

Potassium (K) content in the healthy and BPH infested rice landraces. 


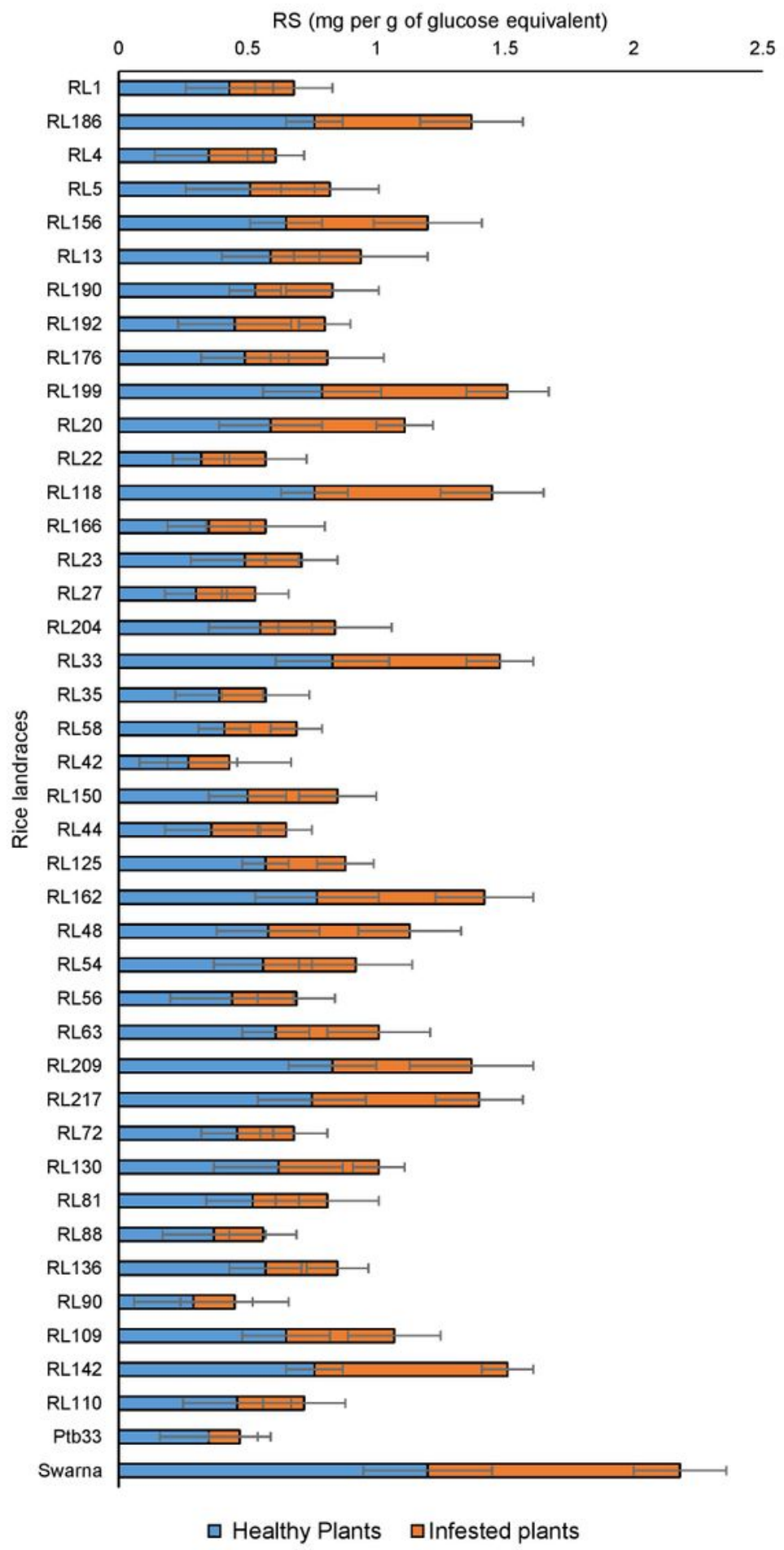

Figure 6

Reducing sugar (RS) content in the healthy and BPH infested rice landraces. 


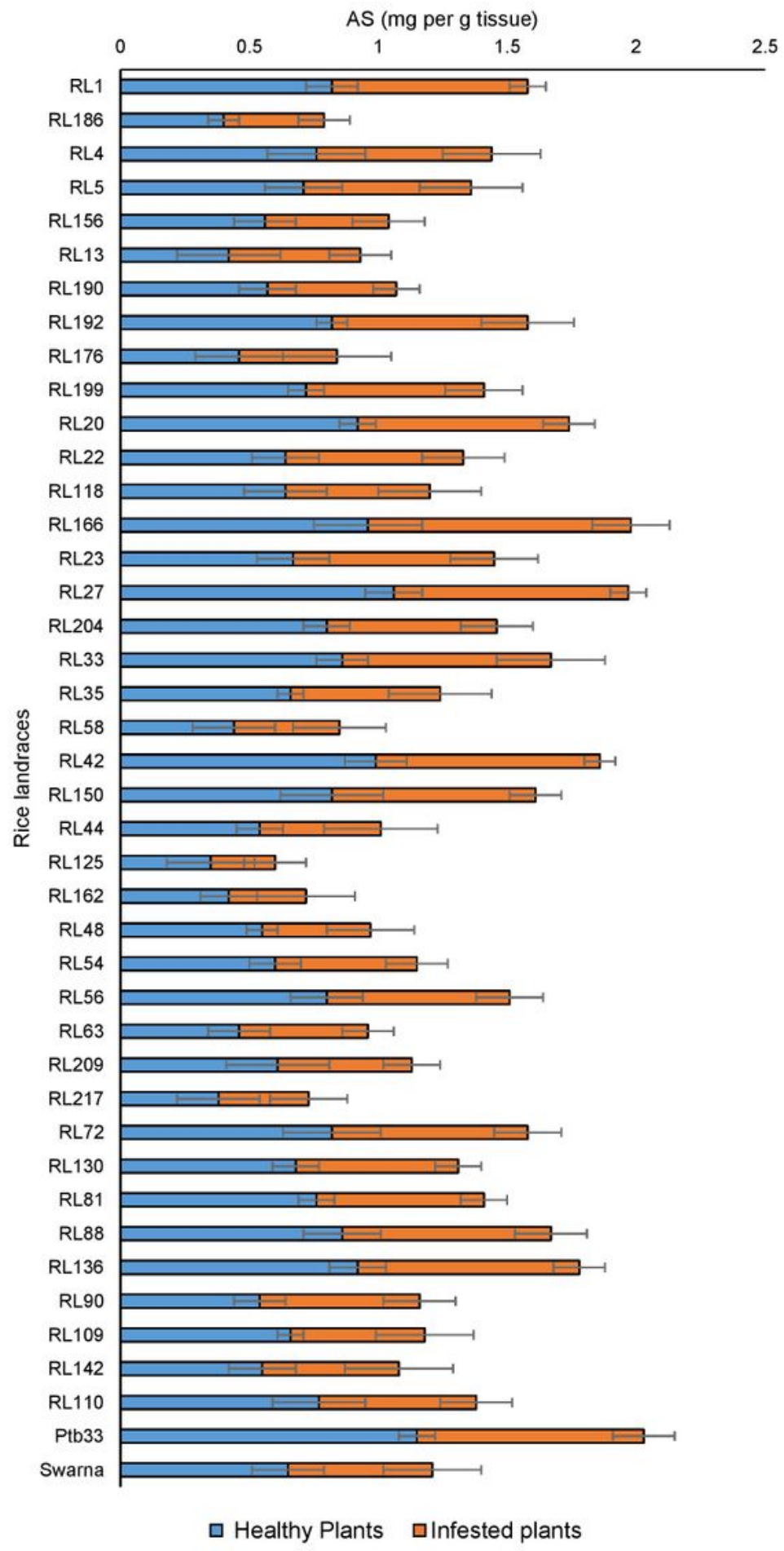

Figure 7

Ascorbic acid (AS) content in the healthy and BPH infested rice landraces. 


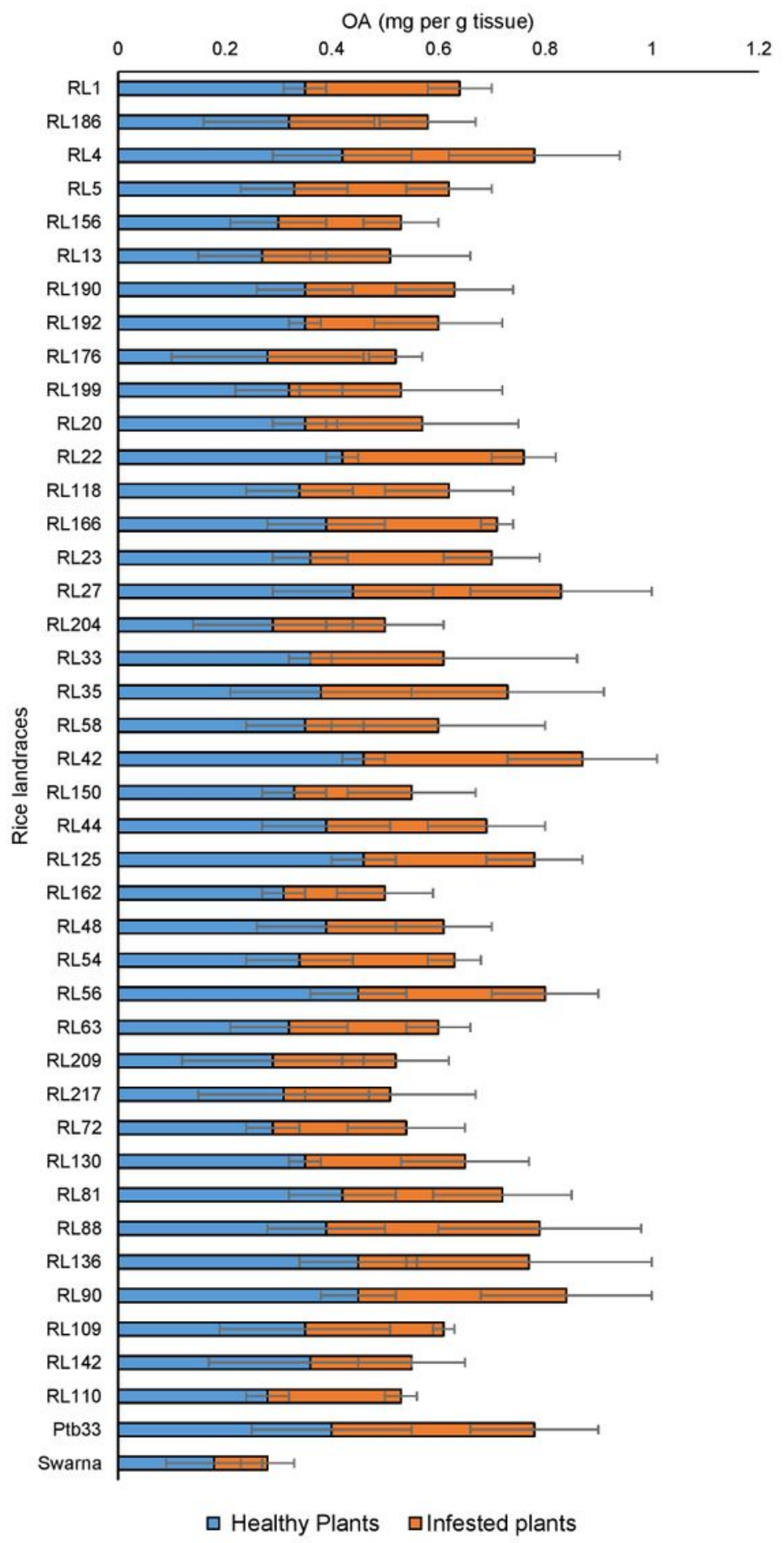

Figure 8

Oxalic acid $(\mathrm{OA})$ content in the healthy and BPH infested rice landraces. 


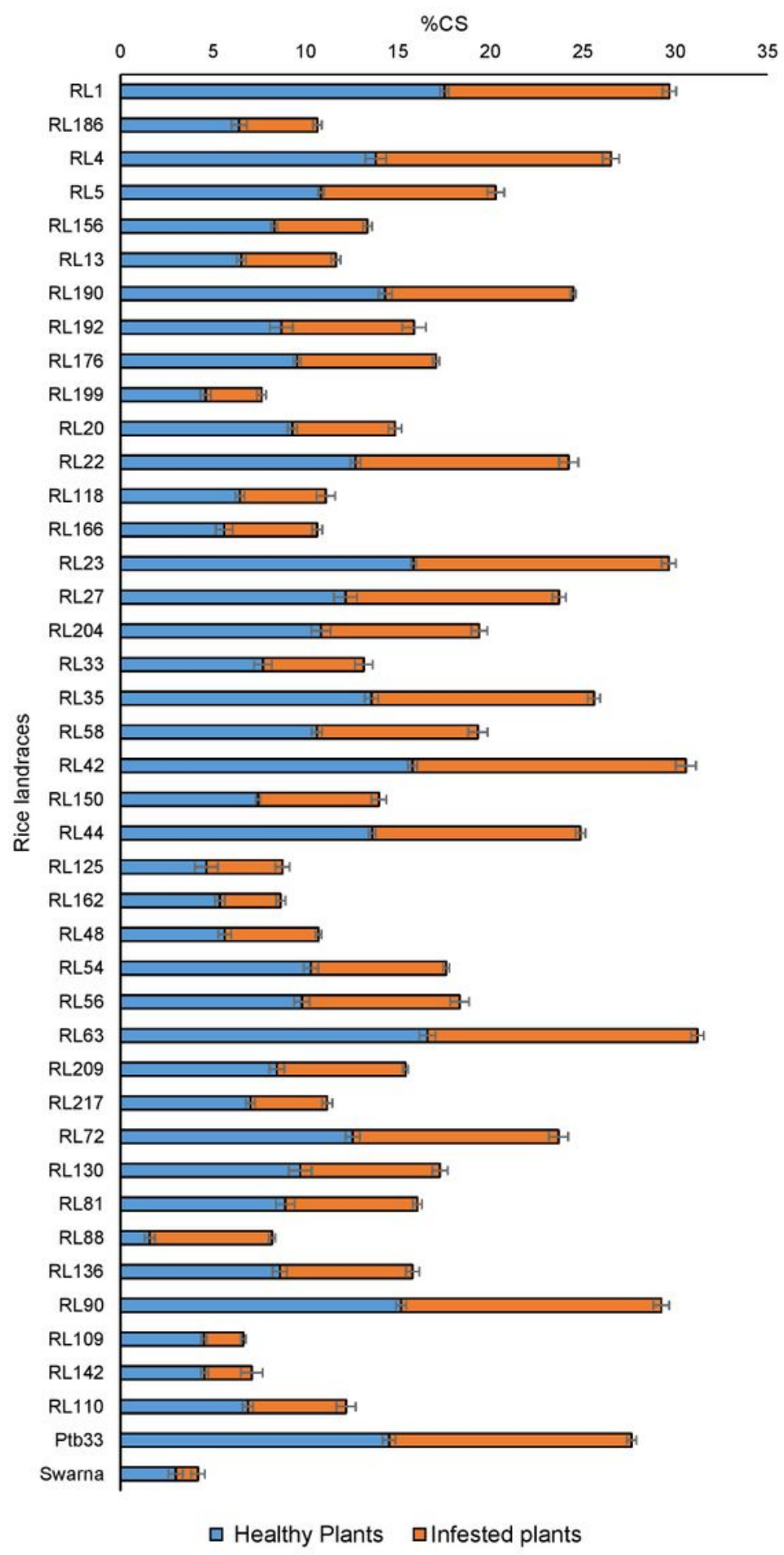

Figure 9

Crude silica (CS) content in the healthy and BPH infested rice landraces. 


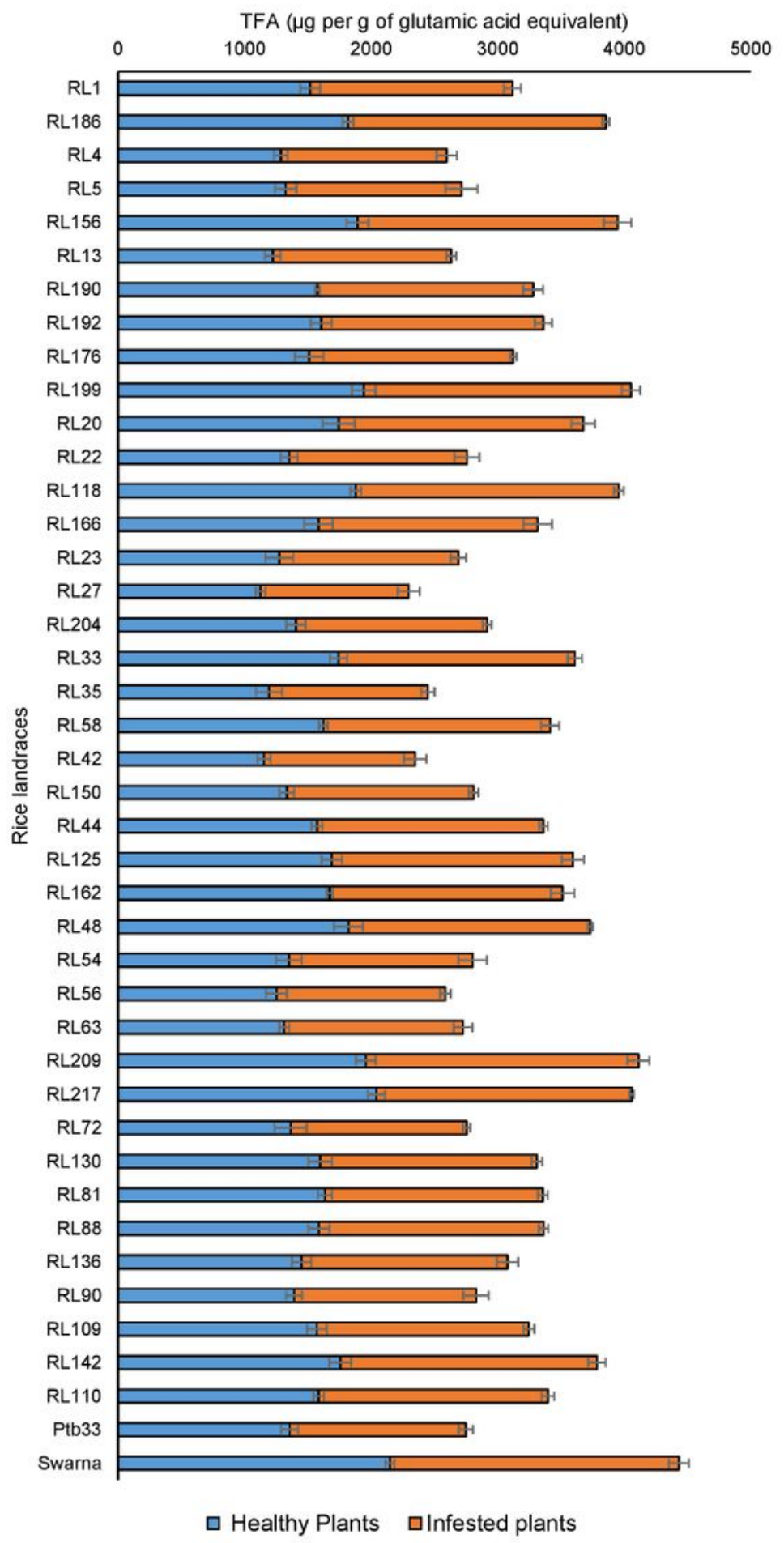

Figure 10

Total free amino acid (TFA) content in the healthy and BPH infested rice landraces. 


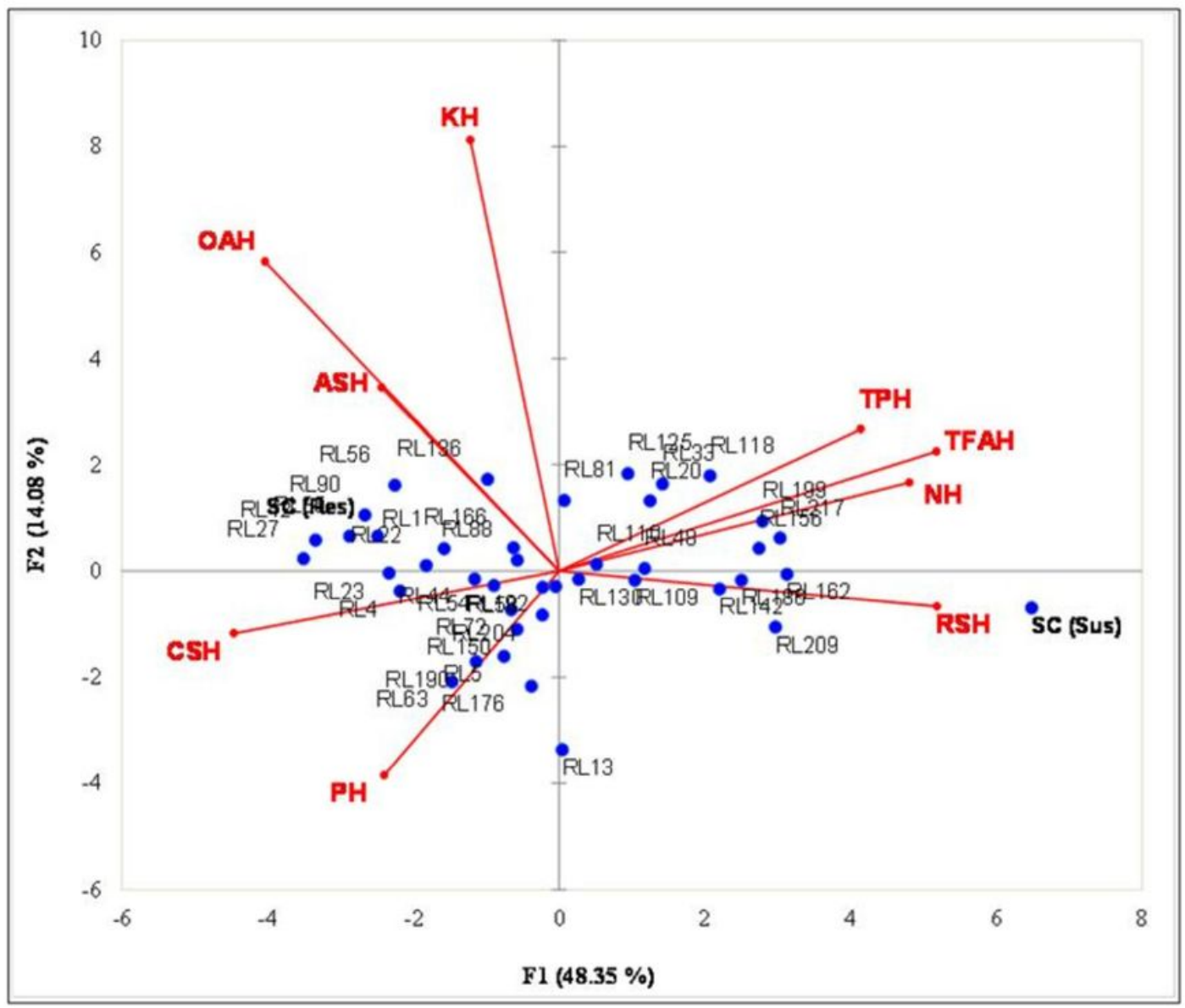

Figure 11

Scattered plot matrix score of healthy $(\mathrm{H})$ rice landraces and biochemical components. 


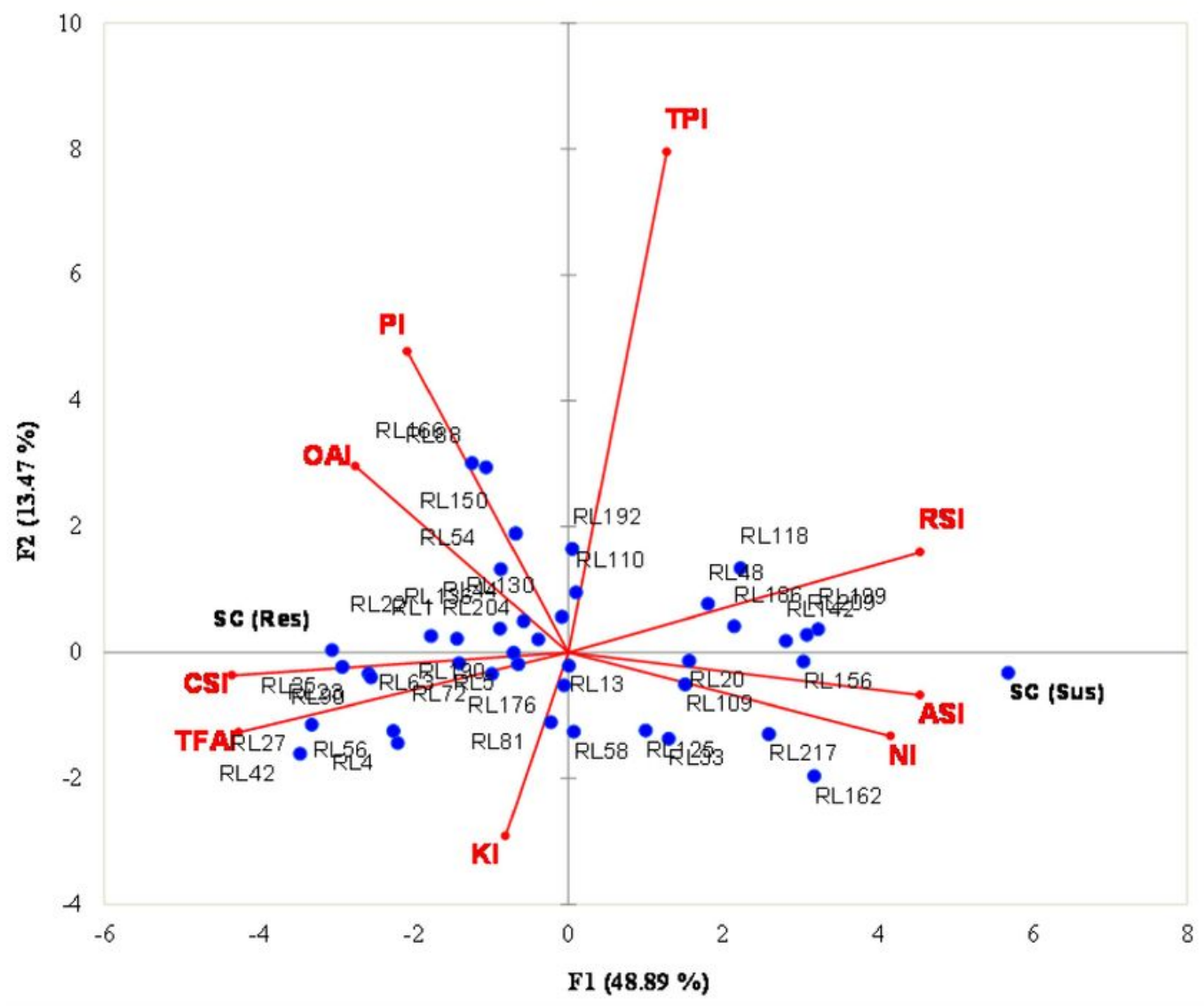

Figure 12

Scattered plot matrix score of infested (I) rice landraces and biochemical components.

\section{Supplementary Files}

This is a list of supplementary files associated with this preprint. Click to download.

- Supplementalmaterial1.pdf 